\title{
El quiebro del PSOE en 1933 (Del Gobierno a la Revolución) \\ I
}

\author{
Víctor Manuel Arbeloa Muru \\ Licenciado en Teología e Historia de la Iglesia. \\ Universidad Gregoriana de Roma. \\ Licenciado en Filosofía. \\ Universidad Complutense de Madrid
}

Recibido: 05.03.2012

Aceptado: 31.05.2012

Resumen. Desde el discurso del ministro Largo Caballero en Ginebra, anterior al del cine Pardiñas y al de la Escuela de Verano (1933), la deriva política del PSOE mayoritario era clara. La salida forzosa del Gobierno aumentó la agresividad frente a la "República burguesa" y a la "democracia burguesa", con la ayuda de las Juventudes Socialistas y del órgano del partido "El Socialista". Los discursos electorales del presidente del partido y las Actas de la comisión ejecutiva de éste son la mejor prueba. La triple derrota electoral de ese año no haría más que exacerbar el sentimiento de frustración. Sólo resistía aún, aunque por poco tiempo, la "facción" de Julián Besteiro, presidente de la UGT: un marxista "ortodoxo", opuesto a la dictadura del proletariado.

Palabras clave: Partido Socialista Obrero Español, Segunda República, Democracia, Revolución.

Abstract. From the speech of Minister Largo Caballero in Geneva, prior to the one that took place in the Pardiñas cinema and the one at the Summer School, (1933), the political leeway of the majority of the PSOE was clear. The forced exit of the Government increased the aggressiveness against the "Bour-geois Republic" and the "Bourgeois Democracy", with the help of the Socialist Youth Association and the official newspaper "El Socialista" ("The Socialist"). The election speeches of the head of the Party and the minutes of the Party-Board are the best evidence of it. That year, the triple election defeat only aggravated the feeling of frustration. The "fraction" of Julián Besteiro, president of the UGT (General Trade Union), an "orthodox" Marxist, opposed to the dictatorship of the proletariat, was the only one resisting, an just for a short time.

Key words: Socialist Party of Spain, Second Republic, Democracy, Revolution.

Sumario: I. La agitada primavera de 1933.-II. El PSOE no abandona el Gobierno.--III. El último Gobierno de Azaña.-IV. El crudo verano de 1933.-V. Dentro y fuera de Gobierno.-VI. El Comité nacional del PSOE (18 y 19 de septiembre).

\section{LA SITUACIÓN POLÍTICA ESPAÑOLA ESTABA MUY AGITADA EN LA PRIMAVERA DE 1933}

El día 7 de enero de ese año, el redactor "Verbo Rojo" escribía en el diario anarco-sindicalista C.N.T., de Madrid: "Nada se salvará. Nuestra lucha en 
campos y ciudades acabará con todo el estamento burgués. El fuego purificador lavará la carroña milenaria, que arrastra y embrutece a los pueblos"1.

Al día siguiente, se declaraba la huelga general en Barcelona, que debía servir de señal para el levantamiento - uno más- planeado en toda España por la FAI (Federación Anarquista Ibérica), creada en 1927 para que sirviera de fermento revolucionario dentro de las estructuras del sindicato mayoritario CNT (Confederación Nacional del Trabajo). Hubo explosiones de bombas, tiroteos, intentos de asalto a cuarteles y combates sangrientos, que dejaron muchos muertos, en Barcelona, Madrid, Lérida, Valencia, Zaragoza, Cuenca, Zaragoza, Sevilla, Oviedo y Gijón. Tarrasa, Sardañola, Lérida y Sallent, en Cataluña; Ribarroja, Pedralba, Bétera, en Valencia; Arcos, Málaga, Utrera, La Rinconada, Sanlúcar, Alcalá de los Gazules, Medina Sidonia y Casas Viejas, en Andalucía, proclamaron el comunismo libertario, que duró unas horas: ocupación de la casa consistorial, quema del archivo de la propiedad, intento de control del cuartelillo de la guardia civil, detención de los principales propietarios, supresión del dinero y reparto de bonos... hasta la reducción de los sublevados por la guardia civil local o venida de fuera.

Se declaró el estado de guerra en los lugares afectados por la sedición, se clausuraron los sindicatos de la CNT y se detuvo al comité peninsular de la FAI y a otros dirigentes "faístas".

Pero la insurrección tuvo su punto más trágico en una miserable pedanía del municipio de Medina Sidonia (Cádiz), llamado Casas Viejas. Fueron los llamados sangrientos "sucesos de Casas Viejas", el día 12 de enero, tras la subversión anarquista que comenzó dos días antes, y la brutal represión por parte de mandos policiales de Asalto. Los 22 campesinos y 3 guardias civiles muertos conmovieron a todo el país, alborotaron a las Cortes y desprestigiaron al Gobierno. El caso sacudió a todos los grupos y personas de bien, sin excluir al partido socialista, a pesar de que en las Cortes estuvo siempre defendiendo al Gobierno de cualquier acusación de complicidad ${ }^{2}$.

${ }^{1}$ ELORZA, A., La utopía anarquista bajo la Segunda República. Precedido de otros trabajos, Ed. Ayuso, Madrid, 1973, p. 454. Sobre el anarquismo y el anarco-sindicalismo en España durante el año 1933 y el resto de la República, su ideología, su organización, sus tendencias y sus divisiones, sus pensadores y sus principales incidentes, todo este lúcido estudio: pp. 351-468.- El joven novelista y periodista aragonés Ramón J. Sender, autor de la novela Siete Domingos Rojos, sobre una huelga anarquista en el Madrid de 1932, publicada ese mismo año, contribuyó notablemente al conocimiento y difusión de la ideología anarquista con ese libro y, además, con los artículos publicados en el diario madrileño $L a$ Libertad durante los días que duró la huelga de enero de 1933 en toda España, y especialmente con los dedicados al levantamiento y represión en Casas Viejas, recogidos después en el libro Viaje a la aldea del crimen, publicado en 1934.

${ }^{2}$ Juan Simeón Vidarte, abogado; hermano "Robespierre" en la orden masónica, con el grado tercero; vicesecretario de la comisión ejecutiva del partido así como de la de Juventudes Socialistas; diputado por Badajoz y primer secretario de la Mesa de las Cortes, perteneciente a la corriente política llamada "centrista", nos dejó en un interesantísimo libro 
Fue una ocasión pintiparada para que, desde el 15 de febrero, los republicanos radicales (PRR) de Alejandro Lerroux -diputado por Madrid-capital con el mayor número de votos dentro de la conjunción republicano-socialista, ministro de Estado en los dos gabinetes provisionales de la República y líder del segundo grupo más numeroso tras el PSOE-, así como otros grupos republicanos menores y toda la derecha, agraviada por el extremoso proyecto de ley de confesiones y congregaciones religiosas, llevaran a cabo una relativa obstrucción parlamentaria. El presidente del Consejo, Manuel Azaña, después de penosas declaraciones para salvar su responsabilidad en la represión en Casas Viejas, tuvo que reconocer la existencia de "ejecuciones fuera de toda legalidad" y destituir al director general de Seguridad, Arturo Menéndez, encarcelado poco después y procesado, aunque su proceso fue revocado dos meses después. No obstante, el Gobierno ganó una y otra vez la cuestión de confianza en la Cámara.

La República ya no es el formidable aparato para fabricar una España más rica y más precisa, en que cada español dé su máximo rendimiento, como soñaba José Ortega y Gasset, unos meses antes ${ }^{3}$. Se ha convertido no sólo en una republiquita tonta, como él temía, sino en una republica enloquecida, compuesta de huelgas y de barullo parlamentario.

Todo el mundo hablaba durante esos meses de crisis y varios partidos políticos deseaban la caída del gabinete. En el Consejo de ministros del día 6 de marzo, el presidente del PSOE, diputado por Madrid-capital y ministro de Trabajo y Previsión Social, Francisco Largo Caballero, le dijo al presidente Azaña, diputado también por la capital, fundador y presidente del tercer partido gubernamental, Acción Republicana (AR), que, si se planteaba la crisis

de recuerdos el dato de que el grupo parlamentario socialista estuvo a punto de pedir la salida de sus tres ministros del Gobierno Azaña, después de lo ocurrido en Casas Viejas. "Yo, cuando ustedes quieran -escribe que dijo Francisco Largo Caballero, presidente del partido y ministro de Trabajo y Previsión Social-, tiro el arpa. Los sucesos de Casas Viejas los llevo clavados en el alma. Es mejor que nos vayamos a casa que soportar esta indignidad". También el presidente de la directiva del grupo, Remigio Cabello, vicepresidente del partido, tenía la misma convicción. Fue Indalecio Prieto, ministro de Obras Públicas, vocal de la dirección nacional y diputado por Vizcaya-capital, quien convenció a sus compañeros para que esperaran a tener más y mejor información sobre lo sucedido. VIDARTE, J. S., Las Cortes Constituyentes de 1931-1933, Ediciones Grijalbo, Barcelona, 1976, p. 522. También en las filas radical-socialistas fue grande la tribulación, de tal modo que pidieron a sus dos ministros, y fundadores del partido, Marcelino Domingo y Álvaro de Albornoz, que salieran del gabinete. El primero de ellos cuenta en sus memorias que amenazó, en caso de que su minoría parlamentaria no votara la confianza al Gobierno, con sólo con dejar el ministerio, sino con dejar de ser diputado y militante radical socialista. Tal vez la misma actitud fue la de Albornoz. El caso es que la minoría votó, a regañadientes, a favor del Gobierno Azaña. DOMINGO, M., La experiencia del poder, Ed. Javier Morata, Madrid, 1934, pp. 288-289.

${ }^{3}$ ORTEGA Y GASSET, J, "Hay que cambiar de signo a la República", Crisol, 13 de julio de 1931. 
y empezaban las consultas, los tres ministros socialistas tenían decidido "retirarse definitivamente del poder y quién sabe por cuántos años. Vamos, que no nos reenganchamos, añade Prieto" ". Los tres ministros socialistas estaban en el Gobierno desde el 14 de abril de 1931.

La participación o no de ministros socialistas en un Gobierno burgués era una cuestión candente dentro de la militancia socialista. El XII Congreso del PSOE, celebrado en octubre de 1932, que eligió a Francisco Largo Caballero como presidente del partido, el dictamen de la ponencia elegida dentro de la comisión "Problemas de táctica" -Ramón Lamoneda, Bruno Alonso, Pascual Tomás, Mariano Rojo y Gabriel Morón- dio lugar, junto a varias enmiendas presentadas, a un largo y polémico debate ${ }^{5}$. El primer punto del dictamen reza que "cumplido el programa que trazó el Congreso extraordinario de 1931, la Ejecutiva elegirá el momento de convocar al Comité nacional para resolver sobre el caso de la participación en el Gobierno". A tenor del segundo punto, "la decisión de separar del Gobierno a los ministros socialistas la adoptará el Comité nacional después de oír a la minoría parlamentaria”. El punto tercero es toda una proclama ideológica de la mayoría de la ponencia: "Estabilizada la República, el Partido Socialista se consagrará a una acción netamente anticapitalista, independiente de todo compromiso con fuerzas burguesas, y encaminará todos sus esfuerzos a la conquista plena del Poder para la realización del Socialismo". El cántabro Bruno Alonso, el más veterano de la ponencia, presentó un voto particular para que el partido diera ya "por terminada su colaboración ministerial", que, si pudo tener su explicación en el movimiento para derrocar la monarquía, "no lo puede tener en lo sucesivo, de acuerdo con el espíritu anticapitalista que informa nuestra historia".

Un grupo de congresistas, encabezado por Indalecio Prieto, diputado por Vizcaya-capital y ministro de Obras Públicas, enmendaba el dictamen en el sentido de que procede "dar por concluida" la participación en el Gobierno "tan pronto como las circunstancias lo permitan sin daño para la consolidación y fortalecimiento de la República ni riesgo para la tendencia izquierdista se-

${ }^{4}$ AZAÑA, M., Diario del 6 de marzo de 1933, Obras completas: Memorias políticas $y$ de guerra, Ediciones Oasis, México, 1968, p. 460.

${ }^{5}$ El Socialista, 12 y 13 de octubre de 1932. Lo esencial, en XIII Congreso del Partido Socialista Obrero Español (Del 6 al 13 de octubre de 1932), Ed. Gráfica Socialista, Madrid, 1934, pp. 561-563. - Sobre el partido socialista en este período, CONTRERAS, M., El PSOE en la II República: organización e ideología, Ed. Centro de Investigaciones Sociológicas, Madrid, 1976, pp. 247-265; JULIÁ, S., Los socialistas en la política española (1879-1982), Ed. Taurus, Madrid, 1997, pp. 183-203. Para los datos biográficos de los políticos socialistas, es imprescindible el Diccionario Biográfico del Socialismo Español (1879-1939), 2 vol., dirigido por Aurelio Martín Nájera, Ed. Pablo Iglesias, Madrid, 2010, y todavía más abundante: http: //diccionariobiografico.psoe.es/. También son muy útiles las obras de este mismo autor, MARTÍN NÁJERA, A., El grupo parlamentario socialista en la Segunda República: estructuras y funcionamiento, 2 vol., Ed. Pablo Iglesias, Madrid, 2000, y Partido Socialista Obrero Español, Ed. Pablo Iglesias, Madrid, 2009. 
ñalada al nuevo régimen en la ley fundamental del Estado y en aquellas otras de carácter complementario ya aprobadas, la cual tendencia debe asimismo asegurarse en las leyes que aún corresponde votar en las Cortes Constituyentes". En un segundo párrafo se añade que "corresponderá en todo momento apreciar si las circunstancias son adecuadas para una separación a la Comisión ejecutiva del partido y a nuestro grupo parlamentario". En caso de no coincidir los dos organismos, sería el comité nacional, convocado con urgencia, el que resolviera la cuestión.

Aprobada su tramitación, hablaron varios congresistas a favor y en contra de la enmienda. Su primer firmante la defendió como más realista y flexible que la de la ponencia, dada la importancia y el peso de los socialistas en la defensa de la República y de sus instituciones y la delicada situación política de España. Si abandonaban precipitadamente el poder a los solos republicanos, se verían obligados a colaborar con ellos en las Cortes, lo que sería mucho peor, a no ser que al día siguiente se lanzasen a la revolución, lo cual sería para todos una desgracia. Besteiro, dejando esta vez su tajante oposición a la participación de los socialistas en un Gobierno burgués, ponderó los riesgos de una separación inmediata de los ministros del partido de sus quehaceres gubernamentales. Más impresión causó el que pronto iba a ser elegido presidente del partido, Francisco Largo Caballero: entendía la cuestión planteada como una cuestión no más que de "táctica". No le parecía bien que "el partido abandonara el papel de actor para tomar el de comparsa". La ocupación completa del poder por los socialistas, en un caso hipotético, tendría todas las instituciones del Estado en contra: burocracia, fuerza pública, magistratura...: "Mientras el capitalismo tenga en su poder la llave de la producción, ¿qué podría hacer un Gobierno socialista, si el capitalismo le boicoteara?". Por eso lo que importa es luchar contra el capitalismo, "responsable de la situación actual". Le dolía al ministro de Trabajo y Previsión Social que se hubieran levantado el país tantas voces a censurar la gestión de los ministros socialistas y "no se haya levantado una sola voz" contra el capitalismo. Según Caballero, el partido "no es reformista", y "siempre ha roto la legalidad cuando ha convenido a nuestra ideas". Se trata, pues, de una cuestión de táctica. La enmienda fue aprobada por el congreso con 23.718 votos contra 6.536 .

En la reunión de la comisión ejecutiva del 8 de marzo $^{6}$, a la que asisten todos sus miembros, plantea el presidente Caballero la conveniencia de fijar posición frente al problema político creado en las Cortes después de "los sucesos de Casas Viejas" y de la obstrucción de la minoría radical, en caso de que se abriera la crisis y los llamara a consulta el presidente de la República. Van todos dando su parecer, coincidente en continuar en un Gobierno de "concentración de la izquierda". Sólo Vidarte se muestra partidario de que, si fuera posible obtener apoyos, la presidencia recaiga en un socialista. Prieto añade

${ }^{6} \mathrm{AH} 20-2$, p. 41. 
a la opinión común negar "toda posible colaboración a un Gobierno de Lerroux", y, en último término, "ver el medio de abandonar el Poder". De los Ríos entiende la oposición en la Cámara al Gobierno por el "desconocimiento que éste tenía de lo ocurrido en Casas Viejas", y dice que el Parlamento da la sensación de crisis "por la falta de entusiasmo en la mayoría"; se muestra contrario a cargar con la responsabilidad de dirigir el gabinete. No le gusta nada al presidente lo dicho por su compañero de gabinete, ya que en todo momento -asevera tajante- se ha procurado desde el Gobierno "el más exacto cumplimiento de la Ley". También él, en caso de crisis, es partidario de un Gobierno de izquierda, presidido por Azaña, "demostrando así la lealtad con que ese hombre ha cumplido con nosotros en el Gobierno", pero "por todos los medios imaginables se debe impedir que el Gobierno de la República derive hacia la derecha, porque destrozaría toda la obra que la República ha realizado". Y termina afirmando que, por su parte, "jamás ocultará aquellas faltas constitucionales que puedan cometer elementos del Gobierno, incluso las que pudiera realizar el Presidente de la República". Aviso a navegantes.

A finales de ese mes, los grupos republicanos de oposición, que deseaban la disolución de las Cortes y la salida de los socialistas del poder, publicaron una primera nota de protesta, redactada por el ex ministro de la Gobernación del primer Gobierno provisional de la República, Miguel Maura, diputado por Madrid-capital y presidente del pequeño partido republicano conservador (PRC). El ex radical-socialista y ahora radical-socialista de izquierda (PRRSI), Juan Botella Asensi, era el principal inductor del proyecto. La nota resultaba muy crítica para el Gobierno, y sobre todo para su presidente, que se mostró muy molesto con ella y en un primer momento sintió la tentación de dimitir ${ }^{7}$.

${ }^{7}$ Ibidem, diario del 14 de abril, pp. 479-482.- Ya en la sesión de la comisión ejecutiva socialista, del 23 de febrero de ese año, se leyó el proyecto de un manifiesto, para ser publicado en su periódico, en el que, frente a la obstrucción parlamentaria llevada a cabo "contra el Partido", se recordaban los compromisos de los que formaron parte del comité revolucionario, y la fidelidad de los socialistas a los mismos. Si un día colaboró el partido, junto a la UGT, en el movimiento revolucionario para derribar al rey Alfonso XIII, fue para cumplir la aspiración primera de su programa mínimo y para ser fieles al manifiesto comunista de Marx y Engels, que recomendaba al proletariado "luchar de acuerdo con la burguesía, siempre que ésta actúe revolucionariamente contra la monarquía absoluta". La única base del pacto con las agrupaciones republicanas fue "un programa de reformas política y sociales". No solicitaron formar parte del Gobierno ni exigieron nada en cuanto al número y calidad de los cargos en él. Tampoco durante los dos años transcurridos han pretendido nada más de lo previamente acordado por el comité revolucionario, y nadie más que ellos han tenido que transigir y constreñirse en sus deseos para llegar a veces al punto de transacción en orden a consolidar y defender la República en todo momento. Otros partidos, que formaron parte del comité revolucionario no deben olvidar sus compromisos con algunas leyes, que ahora critican, "que las aprobaron en Consejo de Ministros, sin discrepar siquiera en los detalles y que las sancionaron después con sus votos en las Cortes". Fundación Pablo Iglesias. Archivo Histórico (AH), 20-2, p. 39.- Por su parte, Alejandro Lerroux, en un libro de memorias, publicado varios años más tarde, escribe: "Desde que 
Llegó el susodicho escrito al despacho del Consejo de ministros en el palacio de las Cortes. "Pregunté -escribe Manuel Azaña en su diario- a los socialistas qué harían en caso de crisis si el Presidente abría las consultas. Caballero dijo que no apoyarían a ningún Gobierno donde hubiese radicales, y que estarían dispuestos a seguir colaborando en otro Gobierno parecido al actual"8. En el posterior Consejo de ministros, mañana del martes, según la misma fuente, "Largo y los otros socialistas decían que los propios adversarios de la colaboración ministerial, dentro de su partido, han cambiado de parecer, en vista de las circunstancias, y que están dispuestos a hacer todo lo necesario para que la maniobra de las oposiciones no prevalezca" .

Por la tarde del mismo día, don Manuel se reunió con el presidente de la República, y en el Congreso con sus ministros para exponerles los puntos de vista de aquél. En esa conversación, y cuando estaba ausente Largo, Fernando de los Ríos, diputado por Granada, ministro de Instrucción Pública y anterior ministro de Justicia, dijo al presidente del Gobierno que no recordaba "que el acuerdo del Partido Socialista, para seguir colaborando aunque se plantease la crisis, fuese tan explícito y terminante como había dicho Largo Caballero". Duda que sorprendió al presidente del Consejo, quien le advirtió que era menester resolverla al momento, porque no podía él ir a plantear una crisis sin saber las soluciones que podía proponer a la presidencia de la República, y que, si los socialistas no estaban dispuestos a seguir en el Gobierno en caso de crisis abierta, su propia conducta tendría que ser muy diferente. Marcelino Domingo, diputado radical-socialista por Tarragona y ministro de Agricultura, puso de manifiesto que la actuación de su grupo dependía en buena parte de la de los socialistas ${ }^{10}$.

Al día siguiente, miércoles, tras nueva audiencia con don Niceto Alcalá Zamora, Azaña vio de nuevo a sus ministros en el Congreso, por la tarde. Las dudas del ministro socialista se habían resuelto: "Fernando de los Ríos -anota Azaña- me dijo que, por la mañana, se había reunido la Comisión ejecutiva del partido, y que el acuerdo era, en efecto, tal como Largo me lo había dicho.

los sucesos del 10 de mayo del 31 le alumbraron con la luz de sus hogueras, me propuse romper aquella coalición o apartarme de ella". La pequeña historia: Apuntes para la historia grande vividos y redactados por el autor, Ed. Cimera, Buenos Aires, 1945, p. 158.

${ }^{8}$ Obras completas... diario del 14 de abril, p. 480.- En la sesión de 8 de marzo, con la ejecutiva al completo, el presidente Largo Caballero planteó la posible respuesta que dar al presidente de la República en caso de que les consultase sobre un nuevo Gobierno, abierta una hipotética crisis tras los sucesos de Casas Viejas y la obstrucción en las Cortes. Todos sus miembros parecieron estar de acuerdo en que ese posible gabinete debiera proseguir la política izquierdista llevada hasta entonces, pero, mientras Wenceslao Carrillo deseaba que Azaña continuase como presidente del Gobierno, "por la rectitud de procedimientos seguidos hasta la fecha", Juan Simeón Vidarte y Pascual Tomás preferían para la presidencia un hombre del partido. AH, 20-2, p. 41.

${ }^{9}$ Ibid., p. 484.

${ }^{10}$ Ibidem. 
Alguien debió de recordar al despistado ministro la sesión de la comisión ejecutiva del día 8 de marzo. Domingo ratificó la situación de los radical-socialistas" $"$.

\section{EL PSOE NO ABANDONA EL GOBIERNO}

A la reunión de la comisión ejecutiva del PSOE (CE) de aquella mañana del 4 de abril de $1933^{12}$, asisten el presidente Francisco Largo Caballero, y los miembros de la misma: Remigio Cabello (antecesor de Caballero en la presidencia y ahora vicepresidente), Enrique de Francisco (secretario-tesorero), Juan Simeón Vidarte (vicesecretario), Pascual Tomás (secretario de actas), y los vocales Wenceslao Carrillo, Anastasio de Gracia, Manuel Cordero, y Antonio Fabra Rivas -casi todos ellos de la llamada izquierda del partido, como su presidente-, además de los vocales llamados centristas Vidarte, Indalecio Prieto y Fernando de los Ríos.

El presidente plantea nuevamente el problema político que al partido le crea la obstrucción de los republicanos y la nota, publicada en la prensa, de oposición a la labor parlamentaria. Pero, como -añade con retintín- los compañeros Prieto y De los Ríos "parecen no recordar lo tratado en la reunión pasada", conviene redactar una declaración en virtud de la cual se puntualicen os criterios del partido. La nota es aprobada por unanimidad:

"La Comisión Ejecutiva, después de examinar las circunstancias políticas creadas por la actitud de las minorías obstruccionistas, estima unánimemente que el actual es el momento menos adecuado para que la representación de nuestro partido abandone el Gobierno, debiendo por consiguiente mantenerse en él y ofrecer nuestra colaboración, si se abriera la crisis, a una solución izquierdista del mismo tono que la actual, negándola, en cambio, de modo absoluto a cualquiera otra solución que variase el rumbo político de la República. La Comisión Ejecutiva acuerda unánimemente expresar este criterio suyo ante el Grupo Parlamentario y ante el Comité Nacional, llegada la ocasión de expresarla ante ellos. A requerimiento de los demás compañeros presentes, declaran Largo Caballero, De los Ríos y Prieto que, como consecuencia de este acuerdo, no se negarían a aceptar los puestos que se les ofrecieran en el Gobierno si, planteada la crisis, se diera a ésta una solución ajustada al criterio de la Ejecutiva".

En aquel momento político, las elecciones municipales del 23 de abril para casi 2.500 ayuntamientos elegidos automáticamente, dos años antes, por el famoso artículo 29, especialmente en Castilla y León, Aragón y Navarra, se vivieron por muchos como un plebiscito a favor o en contra del Gobierno republicano. Aunque nunca se publicaron los resultados oficiales, los partidos gubernamentales obtuvieron algo más del tercio del total de concejales -siendo el partido so-

\footnotetext{
${ }^{11}$ Ibid., p. 485.

${ }^{12} \mathrm{AH}, 20-2$, p. 48.
} 
cialista, entre ellos, el más votado (36'1\%)-, pocos más de los conseguidos por las derechas no republicanas. Los partidos antiministeriales consiguieron, con sus 10.983 concejales, más del doble de los obtenidos por los ministeriales: 5.048. De los partidos republicanos conservadores, el radical fue el más favorecido (58'9\%). El Gobierno hizo lo posible por no dar importancia al acontecimiento.

La obstrucción parlamentaria, tras la aprobación, el 17 de mayo, del dictamen del proyecto de ley sobre Confesiones y Congregaciones religiosas por 278 contra 50, remitió mucho y acabó por diluirse tras una serie de componendas y una especie de tregua ofrecida por el presidente del Consejo a los grupos de oposición, sobre todo al PRR, representado para esos menesteres por Diego Martínez Barrio, diputado por Sevilla capital y ex ministro de Comunicaciones en los dos Gobiernos provisionales del nuevo régimen ${ }^{13}$. Pero la posición del Gobierno no fue por eso mucho más estable. La mala situación del país, las intrigas de los radicales, más una serie de supuestos agravios de los que se sintió víctima el presidente de la República en su alta magistratura, y las tirantes relaciones personales de éste con Azaña fueron minando la mutua confianza necesaria y el cambio de Gobierno, con pretexto de la necesaria sustitución de uno de los ministros y la división de un ministerio, se hizo inaplazable.

En su diario de 26 de mayo escribe el presidente del Gobierno español tras una agria y tensa audiencia con don Niceto: "Salgo con una impresión muy desagradable. Está visto que no nos entendemos. El Presidente no puede aguantar al Gobierno, ni a mí personalmente. Quiere hacer una política de "derechas" y anda buscando la ocasión de derribarnos sin comprometerse demasiado. Esto se acaba, porque estando así el Presidente, rayano con el odio personal, aunque no nos dé un golpe político, difícilmente podremos marchar juntos. Cada día será un disgusto"14.

El segundo partido gubernamental en número de diputados, el republicano radical socialista (PRRS), que ya había sufrido una pequeña escisión, estaba profundamente dividido en cuanto a política gubernamental, participación en el Gobierno y salida de la crisis. Su IV congreso ordinario, del 3 al

${ }^{13}$ Sobre la obstrucción, vista por los radicales, MARTÍNEZ BARRIO, D., Memorias, Ed. Planeta, Barcelona, 1983, pp. 174-181.

${ }^{14}$ Obras completas, IV..., p. 552.- Según Martínez Barrio, ya en mayo el presidente de la República pensaba en un Gobierno-puente, de "pasarela", de concentración republicana, sin la presencia de Manuel Azaña, que aprobase el presupuesto y convocara elecciones municipales; en febrero o marzo del año siguiente, sería la hora de Lerroux, que disolvería las Cortes. Para don Niceto, el presidente del Consejo, con un pasivo idéntico o superior al de los socialistas, carecía de "activo, es decir, de confianza cerca de la opinión y de fuerza orgánica dentro de los partidos". Pero Barrio no veía un gabinete sin Azaña con las mismas Cortes. Memorias, pp. 186-188. Confirma este plan político el jefe del Estado en sus memorias, reescritas después de la guerra, al haberle sustraído el Gobierno de la República, tras el inicio de la guerra, las originales, depositadas en el Crédit Lyonnais de Madrid. AlCALÁ ZAMORA, N., Memorias, Ed. Planeta, Barcelona, 1998, p. 282. 
8 de junio, todavía pudo evitar por un corto tiempo una crisis mayor: aprobó, tras largas tensiones, un comité ejecutivo nacional unitario y reafirmó la continuidad de las Constituyentes así como la conveniencia de la colaboración socialista ${ }^{15}$.

Ese mismo día 8, se abría crisis de Gobierno. La grave enfermedad del ministro de Hacienda, Jaime Carner, diputado independiente por Barcelona capital, dentro de Esquerra Republicana de Cataluña (ERC), y la excesiva acumulación de funciones en el ministerio que antes se llamó de Fomento y ahora de Agricultura movieron al presidente del Gobierno a plantear al presidente de la República la reestructuración del gabinete, cuya aceptación llevaría implícita la reafirmación de confianza. Pero Alcalá Zamora declaró que en tan delicada situación, había de consultar a los partidos políticos, lo que equivalía a una implícita negativa de aquélla. Y la dimisión del Gobierno fue inmediata.

De "atrocidad, no por esperada, menos grave", calificó Azaña la actuación de don Niceto $^{16}$.

El presidente de la República fue encomendando sucesivamente a los tres principales partidos gubernamentales la nueva tarea, por orden de importancia. Pero después convocó también al palacio de Oriente a personalidades de la vieja política, como Santiago Alba, Felipe Sánchez Román, Melquíades Álvarez o Ángel Ossorio y Gallardo, así como a intelectuales de la talla de Ortega o Marañón, todos ellos, eso sí, diputados a Cortes. El primer llamado a evacuar consultas fue Julián Besteiro, diputado socialista por Madrid capital, presidente de las Cortes Constituyentes y presidente del sindicato socialista UGT.

Por eso a la sesión extraordinaria de la CE del PSOE, en esa misma fecha ${ }^{17}$, asistió, invitado, el presidente de la Cámara. Éste fue del parecer que debía prolongarse la vida de las Constituyentes y formarse un Gobierno con mayoría parlamentaria, encargando de esta misión al grupo o federación de grupos más numeroso del Congreso de los diputados, y, en caso negativo, proseguir con los menos numerosos. Besteiro según el acta, "se permitió indicar que, de ofrecerse el Gobierno al partido socialista, debía requerirse al compañero Largo Caballero y encargarle de esta gestión. Relata después cómo en la noche del día 8 fue llamado a palacio donde se le confió la misión de formar Gobierno que él no aceptó, por creer que su opinión tantas veces expresada

${ }^{15}$ Una obra muy útil para conocer la evolución de los principales partidos republicanos es la de AVILÉS FARRE, J, La izquierda burguesa en la II República, Madrid, 1985, que se basa sobre todo en los textos oficiales de esos partidos, así como en varios periódicos de Madrid. Sobre el partido republicano radical en este período, RUIZ MANJÓN, O., El Partido Republicano Radical 1908-1936, Ed. Tebas, Madrid, 1976, pp. 355-441.

${ }^{16}$ AZAÑA, M., Diarios 1932-1933: Los cuadernos robados, Ed. Crítica, Barcelona, 1997, p. 341.

${ }^{17} \mathrm{AH}, 20-2$, pp. 61-62. 
de que el partido socialista no debía participar en el Poder, se lo impedía. A pesar de esto, el Presidente le rogó aplazase su contestación definitiva hasta el día siguiente, y esto ha hecho, pero continúa con la misma disposición de ánimo que entonces".

Largo Caballero cree que la llamada debe entenderse "como una apelación al Presidente de la Cámara, pero no como requerimiento al Partido no prejuzgando nada la respuesta de este compañero sobre la determinación que el Partido Socialista haya de tomar si se le ofrece el Poder llamando a otra persona en la que no concurran esas especiales circunstancias".

A esta seca y malhumorada advertencia del presidente del partido, el primer encargado de formar Gobierno responde, realista, que en nada obliga al partido su decisión, pero no sin hacer patente que el jefe del Estado hizo constar que le llamaba no como presidente de las Cortes, sino como socialista. En este punto Azaña coincidía con Largo.

Indalecio Prieto, diputado por Vizcaya-capital, ministro de Obras Públicas, y ex ministro de Hacienda, que siempre ha disentido de Besteiro en este punto, le pregunta, una pizca malicioso, si es irrevocable su decisión. Al contestarle éste que sí, y que ni aun en el caso de indicárselo la comisión ejecutiva podría aceptar, pues "a su entender no se tata de caso de disciplina", el político bilbaíno juzga que su compañero "debe recalcar que su contestación no prejuzga la del partido, para evitar con ello que pueda eliminarse a nuestro grupo sin consultarle". Que es, como ministro, lo que en verdad teme.

El presidente de las Cortes, que ya ha expresado antes lacónicamente su pensamiento, entiende bien lo que ahora se le pide y promete que "comunicará al Presidente que el partido ha respetado su resolución como actitud personal, pero sin prejuzgar la resolución del propio partido, que ya estudiaría este problema, si se daba el encargo de formar Gobierno a otro camarada en quien no concurrieran estas circunstancias". Dicho esto, abandona, discreto y seguramente mohíno, la reunión ${ }^{18}$.

${ }^{18}$ Azaña nos desvela cuál era la opinión del dirigente socialista en este punto. Según su diario de 30 de abril, el presidente del Consejo se encuentra con el de las Cortes en la embajada francesa: "Besteiro se inclina a una solución que consistiría en rehacer la coalición de los primeros meses de la República, pero dejando en el Gobierno un ministro socialista nada más". Por cierto, a renglón seguido, el autor de este dietario añade que de todo el Gobierno los ministros socialistas "son los que están más descontentos de la conducta de Besteiro en la presidencia de las Cortes. No nos ayuda en nada". Le reprocha en gran parte la lentitud del curso del Parlamento y el retraso en la aprobación de algunas leyes, así como su tolerancia ante los incidentes que suscitan las oposiciones, el no corregir a tiempo "los desmanes de los levantiscos, etcétera, etcétera". En sus apuntes posteriores vuelve Azaña en varias ocasiones a quejarse de la falta de colaboración del presidente de la Cámara. A tenor del mismo diario, del 18 de mayo, en una de esas ocasiones, dice Largo hablando de su compañero: "Se cree un virrey". En cuanto a la participación socialista en el Gobierno, el presidente del Gobierno deja en claro su propia posición, Su intención era llegar a las elecciones generales cuando las Cortes acabasen de hacer su tarea, y era muy 
La CE, después de un breve cambio de impresiones, acuerda dar a la prensa la siguiente nota: "La Comisión Ejecutiva del Partido la oído las explicaciones del camarada Julián Besteiro respecto a la forma en que el Sr. Presidente de la República le ha confiado el encargo de formar Gobierno y su resolución de declinar este encargo, resolución que mantendrá aun cuando la Comisión Ejecutiva le aconsejara proceder en sentido contrario, por considerar que su criterio personal opuesto a la participación del Partido socialista en el Poder, y que expuso cuando ésta se decidió, le obligan a una conducta en consecuencia con dicho criterio. La Comisión, respetando la actitud personal de Besteiro, estima que ella no puede prejuzgar la del partido, la cual será definida si el mandato deformar Gobierno llegara a ofrecerse a algún afiliado en quien no concurran las circunstancias tan especiales como las que concurren y eran públicas en el mencionado camarada".

Se reanudó poco después la sesión de la $\mathrm{CE}$, con los mismos componentes, en una sala del Congreso de los diputados. Tras exponer Caballero su opinión sobre los motivos de la crisis, se acuerda que, de ofrecérseles de nuevo la cabecera del banco azul, no se acepte sin antes haber hablado con el presidente del Consejo y los demás ministros dimisionarios, y si cualquiera de ellos pusiera el menor inconveniente, declinar ese honor.

Dicho y hecho. El camarada Indalecio Prieto, que había sido llamado poco antes a palacio, regresa diciendo que se le ha encargado de formar "un Gobierno de amplia concentración republicano-socialista. Se acuerda lógicamente, siguiendo la decisión anterior, no entrar a examinar el fondo del problema sin antes visitar a Azaña y los demás ministros dimisionarios". Suspendida la sesión hasta las cuatro de la tarde, el ministro de Obras Públicas en funciones, que vuelve contentísimo y elegantemente vestido, informa de la reunión tenida con el aún el presidente del Consejo y con el Gobierno dimisionario, "así como del ofrecimiento de colaboración que le han hecho los demás ministros. Cree poder conseguir la cooperación personal de Azaña".

El primer jarro de agua fría sobre quien ya se las prometía felices viene de su colega en el gabinete, Fernando de los Ríos, para quien "un Gobierno con la Presidencia de un socialista no conviene en esos momentos ni a los intereses generales ni a los del Partido, ya que no podrá hacerse labor alguna socialista, pues la situación económica mundial es cada día más grave y que sus lógicas repercusiones en España habrán de ser atribuidas a la Presidencia de un socialista" 19 .

conveniente dar por terminada la obra del Gobierno "a su tiempo y en paz, para que los socialistas se retirasen del poder sin enojo ni despecho. Una etapa de gobierno republicano, sin socialistas, antes de las elecciones, sería muy útil". Pero las oposiciones hacen todo lo necesario, a su entender, para que ninguna de las dos cosas se realice. Obras completas, IV ..., pp. 500, 533 y 502, respectivamente.

${ }^{19}$ Sobre Fernando de los Ríos en este período, ZAPATERO, V., Fernando de los Ríos: Biografia intelectual, Ediciones de la Diputación de Granada, Granada, 1999, p. 391 y ss. 
Por el contrario, los demás colegas de la comisión ejecutiva se complacen, en diferentes grados, con el encargo presidencial a "don Inda", como familiarmente le llaman. El vicesecretario Vidarte afirma que no es posible vacilar, pues de no aceptarse, teme que se confiera el honor al partido radical. Opina De Gracia que deben continuarse las gestiones para formar Gobierno procurando llegar a un acuerdo con las otras minorías gubernamentales sobre el programa que realizar. Lo mismo sostienen Cabello y De Francisco. Carrillo añade que el próximo Gobierno debe dar "preferente atención" a la reforma agraria. El presidente del partido estima que, "dada la gravedad del momento presente, no debe el Partido Socialista rehuir esta responsabilidad, pero la presencia de un socialista en la cabecera del banco azul obliga a una orientación más de izquierda en el nuevo Gobierno". La ley del control obrero, que él no pudo desatascarla en la Cámara, le parece al ministro de Trabajo y Acción Social una prueba de esa nueva orientación.

Prieto está conforme con la orientación dicha, pero cree que "no debe ponerse como condición que esta ley sea la primera que se ponga a discusión, aunque vaya incluida en el plan a realizar del nuevo Gobierno". Tras nuevas aclaraciones de Largo y de Los Ríos, se acuerda por unanimidad "continuar las gestiones para formar Gobierno y exponer este criterio ante la Minoría parlamentaria" 20 .

La minoría, mayoritariamente "caballerista" aprobó el mismo criterio por 61 votos contra 9. Y todos los partidos del arco gubernamental estuvieron acordes. Pero don Niceto pidió a su buen amigo personal que consiguiera la entrada de los radicales en el nuevo Gobierno, extremo que Prieto compartía en principio, y al que se opuso en redondo Largo Caballero, fiel a sus convicciones antes manifestadas. "Pero se ha atravesado Largo", cuenta Azaña que dijo Prieto, quien quiso contar en su equipo a toda costa con el político alcalaíno ${ }^{21}$. La minoría socialista, muy reducida

En Fernando de los Ríos: Obras completas, en cinco volúmenes, edición de Teresa Rodríguez de Lecea, Ed. Anthropos, Madrid, 1997, no aparece escrito alguno del político socialista durante el año 1933, y en el estudio preliminar, escrito por la editora, ni siquiera se menciona su actividad en estos meses decisivos.

${ }^{20}$ Desde el 4 de mayo de 1933 hasta octubre del mismo año componían la directiva del Grupo Parlamentario Socialista (GPS), el presidente, Remigio Cabello, diputado por Valladolid; el vicepresidente, Enrique de Francisco, diputado por Guipúzcoa, ambos miembros de la CE; el secretario, José Ruiz del Toro, diputado por Murcia-provincia, y los vocales, Trifón Gómez y Andrés Saborit, ambos diputados por Madrid-capital, representando a la UGT. Desde octubre de 1933, Caballero ocupó la presidencia del GPS. Tuvo como vicepresidente a Juan Negrín, vocal de la misma directiva desde julio de 1931 a mayo de 1932, diputado en las Constituyentes por Las Palmas de Gran Canaria, y diputado por Madrid-capital tras las elecciones de 1933; y como secretario a Ramón Lamoneda, diputado por Granada a la vez que secretario cuarto de la Mesa de las Cortes en la legislatura 1933-1936.

${ }^{21}$ Diarios 1932-1933..., p. 350.-También el presidente Alcalá Zamora es de la misma opinión, al comentar que "Besteiro y Prieto fueron obligados a renunciar por la actitud irreductible de Largo Caballero empeñado en ser el presidente”. Memorias..., pp. 277- 
de presencias esta vez, rechazó la entrada del PRR en el Gobierno por 28 votos contra 13 y 4 abstenciones ${ }^{22}$.

El tercero llamado a palacio, en representación del PPRS, fue el ministro de Agricultura en funciones Marcelino Domingo, triunfador en el reciente congreso de su partido, quien, sin consultar siquiera a los radicales, renunció

278. Más adelante, explica por qué no le fue posible llamar al presidente del partido para formar Gobierno, pero, quizás por escribir mucho después del acontecimiento, confunde fechas y situaciones: la" alarma causada" por el discurso de Ginebra [que llegó más tarde, como veremos] lo hizo del todo imposible, "por razones imperiosas de tranquilidad social". Así se lo explicó personalmente, aunque no logró calmarle. Y eso que Largo se consideraba, "y no sin razón, el ministro más íntimo amigo mío", escribe don Niceto. "Sobre todo lo que le enfureció más - añade- fue el encargo a Prieto, que éste no agradecería y el primero no perdonaba". La cosa es que, al igual que nos ha contado Azaña de sí mismo, al cesar los ministros del último Gobierno azañista en septiembre, fue Largo el único que no hizo al presidente de la República la visita acostumbrada de cortesía, y el único que se negó a dar posesión a su sucesor en la cartera, Ricardo Samper, republicano radical. En cambio, más fácil comprensión halló a la hora de formar el Gobierno en Fernando de los Ríos, "quien se hizo cargo de que por motivos de paz religiosa no le podía encargar a él”. Ibidem, pp. 294-295.

${ }^{22}$ Juan Simeón Vidarte, nos relata vívidamente todo el proceso. Según él, don Niceto obligó a Prieto a "requerir" a los radicales a entrar en el nuevo Gobierno con 2 ó 3 representantes, lo que fue excesivo hasta para Prieto y sus deseos de ser el primer socialista que ocupara en la historia de España una presidencia de Gobierno. En la discusión del grupo parlamentario encaja Vidarte la afirmación de Largo Caballero de que "cada día consideraba más necesario apelar a las masas obreras y desenmascarar a los hombres de la República", mientras Prieto declaró entonces que no consideraba madura a España para la revolución socialista: "Si ése es el camino, que quiere señalar la minoría, que no se cuente conmigo". En cuanto a esa segunda votación, tras dar los números del resultado, añade el primer secretario de las Cortes: "y los 72 restantes [diputados socialistas] habían tomado la decisión heroica de abandonar el salón". Lo que él atribuye a la división ideológica mostrada por sus dirigentes. Prieto convocó al día siguiente en un salón del edificio de las Cortes a todos los diputados de la mayoría gubernamental y a los medios de comunicación, y les contó lo sucedido, lo que irritó a los grupos que habían compartido el poder con el ministro todavía en funciones. Un grito anónimo salió de entre la masa: " ¡Muera el Botas!" (mote popular de don Niceto Alcalá Zamora, por su calzado habitual). Las Cortes Constituyentes..., pp 587-597. - FLC, que en su libro de memorias llega a dar a don Niceto el calificativo de "el Judas de la República", justifica el rechazo del encargo no a Prieto, sino a los "correligionarios de Lerroux", por ser un descrédito para el partido socialista, "pues a más de que la historia de Lerroux siempre fue con justicia combatida por el Partido por su significado inmoral, en aquel momento estaba marcado con el sello deshonroso de haber defendido a Juan March, conocido como "el último contrabandista". Tras la decisión del grupo parlamentario -sigue diciendo Largo-, "Prieto tuvo que declinar los poderes. Imagino que esto le debió llegar al alma, por no haber comprendido el verdadero significado y el sentido moral de mi oposición". Añade que desde entonces no desaprovechó ninguna ocasión "para satisfacer su rencor", y que sus amigos aprovecharon el incidente para culparle a él de haberle impedido formar Gobierno, llegando a afirmar que, de haberlo formado, "podía haberse evitado la guerra civil". Y concluye: "El caso es que un incidente sin gran importancia - un caso de amor propioha servido de motivo para causar grandes males al Partido y a la Unión General de Trabajadores". LARGO CABALLERO, F., Mis recuerdos: cartas a un amigo. Con prólogo y notas de Enrique de Francisco, Ediciones Unidas, Méjico, 1954, pp. 145-146. 
al empeño ${ }^{23}$. Y entonces, pese a la primera intención de Alcalá Zamora, que era prescindir de los servicios del presidente de Consejo en funciones y presidente a la vez de AR, al fin y a la postre fue éste el encargado de formar el nuevo Gobierno de amplia base. Pero Azaña tampoco pudo conseguir la entrada de los radicales. "Si los socialistas salen, los radicales estarán en la mayoría, aunque no tengan ministros", le dijo Martínez Barrio, amenazándole veladamente, en caso de componer un gabinete parecido al anterior, hasta con el abandono de la Cámara. El formador del Gobierno no pasó por esa condición, imposible en ese momento de cumplir ${ }^{24}$.

El día 12 del mismo mes de junio, asisten a la reunión de la $\mathrm{CE}$ todos sus miembros - con las ausencias justificadas de Tomás y De Francisco-, así como doce delegados regionales de Andalucía, Asturias, Baleares, Castilla la Nueva, Castilla la Vieja, Cataluña, Galicia, Levante, Marruecos y Vizcaya, miembros todos ellos del comité nacional ${ }^{25}$. Largo Caballero. expone la situación política, Hace historia de la obstrucción parlamentaria, cuya "verdadera finalidad" es la de "impedir la aprobación de la Ley de Congregaciones", $\mathrm{y}$, aunque la comisión ejecutiva y la minoría parlamentaria socialista han actuado de acuerdo, ha querido contar con la opinión con los miembros del comité nacional, todos los cuales, junto con la dirección del partido, aprueban por unanimidad "la actuación de la Comisión Ejecutiva en relación con la participación en el Poder".

En ninguna de las preguntas de los delegados regionales, de poco fuste, ni en las respuestas de Caballero se hace alusión alguna a Casas Viejas, a las elecciones municipales de abril, a la precaria situación económica o a las revueltas y huelgas por toda España. La obstrucción no se debía sólo, como Azaña y Largo declaraban, a la ley de Congregaciones. Pero la minoría republicana radical, la más eficazmente obstruccionista, no tuvo reparo alguno en aprobar dicha ley y en justificarla por medio de su portavoz en la sesión del 17 del pasado mes de mayo.

Tras las intervenciones de los delegados de Levante y Cataluña, se ausentaron los tres ministros socialistas dimisionarios, seguramente camino de palacio, y la sesión perdió todo interés. El objetivo estaba alcanzado.

\section{EL ÚLTIMO GOBIERNO AZAÑA}

El nuevo gabinete quedó formado aquel 12 de junio. Los tres ministros socialistas permanecieron en el poder: sólo que De los Ríos se hizo cargo de la cartera de Estado, sustituyendo al independiente Luis de Zulueta, diputado independiente por Badajoz, dentro de la conjunción republicano-socialista, y

${ }^{23}$ Domingo asevera que no quiso prescindir de Manuel Azaña, como presidente del Gobierno que se le encargó, y que él hubiera repetido tal cual, y por eso devolvió pronto los poderes. La experiencia del poder..., p. 304.

${ }^{24}$ Diarios 1932-1933..., p. 356.

${ }^{25} \mathrm{AH}, 20-2$, pp. 63-65. 
siendo sustituido en Instrucción Pública por el catedrático madrileño radicalsocialista Francisco José Barnés Salinas, hombre relevante en la Institución Libre de Enseñanza junto a su hermano Domingo, diputado por Ávila y vicepresidente de las Cortes. El puesto de Carner lo ocupó el catedrático de Hacienda en la universidad de Madrid, Agustín Viñuales, militante de AR, director general del Timbre en el anterior ministerio de Prieto, y en aquel momento delegado del Gobierno en el Banco de España, quien se negó hasta última hora a los repetidos ofrecimientos de Azaña. Para cumplir con la cuota catalanista, el líder de ERC, Luis Companys, diputado por Barcelona capital, se hacía responsable del ministerio de Marina, que abandonaba José Giral, diputado de AR por Cáceres, amigo personal de don Manuel, quien seguía manteniendo, además de la presidencia, la cartera de Guerra. Para el viejo republicano federal José Franchy y Roca, diputado por Las Palmas de Gran Canaria, era el nuevo ministerio de Industria y Comercio, separado por vez primera del de Agricultura, en manos antes y ahora de Marcelino Domingo, aferrado al mismo, a pesar del interés del presidente por trasladarle de allí, donde le veía incapaz, al ministerio de Instrucción, en el que se había estrenado como ministro ${ }^{26}$. Franchy pidió, entre otras cosas, a Manuel Azaña que los socialistas no tuvieran la cartera de Trabajo, pero aquél no le hizo caso ${ }^{27}$.

Nada mejor para conocer el momento político del nuevo Gobierno que la sesión parlamentaria del día 14 de junio, en la que el presidente Azaña presenta al nuevo Gobierno, explica someramente la génesis de la crisis, los cambios habidos en el ministerio y el perfil de los nuevos ministros ${ }^{28}$. Confiesa que durante la crisis, el presidente de la República tuvo a bien contarle cada noche lo acontecido durante la jornada. Y nos desvela la fórmula con la que el jefe del Estado le encargó la misión de formar el nuevo gabinete: "Procure usted formar un nuevo Gobierno ampliando en lo que pueda la mayoría actual, y donde pueda usted, lo hace, y donde no, forme usted el Gobierno que sea posible".

${ }^{26}$ Domingo, en cambio, hace de la continuación en el ministerio, en aquel mal momento, una cuestión de honor patriótico. La experiencia del poder..., p. 304.

${ }^{27}$ Faltaba en la lista gubernamental Álvaro de Albornoz, que nunca faltó en ningún gabinete desde el 14 de abril, ya como ministro de Fomento, ya como titular de Justicia. Albornoz, uno de los fundadores del partido republicano radical-socialista junto con Marcelino Domingo, abogado, escritor y exaltado orador, fue elegido el día 3 de julio por las Cortes presidente del Tribunal de Garantías Constitucionales, que se constituyó el 2 de septiembre siguiente.- A Vidarte le debemos la confidencia de que Largo Caballero ofreció ese cargo a su dilecto consejero, el periodista y escritor Luis Araquistain, ex comunista, diputado a Cortes Constituyentes por Vizcaya-capital, miembro de la comisión constitucional, subsecretario del ministro de Trabajo en 1931, embajador de España en Berlín en 1931-1932. Pero Araquistain declinó el ofrecimiento, por no ser jurista. Las Cortes Constituyentes..., p. 610.

${ }^{28}$ Cortes Constituyentes, vol. 9, núm. 353, 14 de junio de 1933, pp. 4-30. El discurso programático de Azaña, pp. 4-10. 
Azaña no consiguió la participación del partido radical tras entrevistarse personalmente con Lerroux. Éste lo explica en un abundoso discurso, siempre barroco, polémico y a la vez cordial, y en una réplica posterior ${ }^{29}$, interrumpido frecuentemente por varios diputados socialistas, entre ellos, Prieto. Desde el primer Gobierno constitucional Lerroux estaba en contra de la participación de los socialistas en los gabinetes republicanos, Una vez aprobada la Constitución, debían haber abandonado el Gobierno, fiscalizando al mismo; el resto de la obra postconstitucional era cosa de los partidos republicanos. El viejo jefe radical dedica mucha atención a la labor social de los socialistas y sobre todo a su aplicación en la España de su tiempo. Citando extensamente unas declaraciones del catedrático republicano y santón jurista, diputado independiente por Madrid-capital, Felipe Sánchez Román, pondera las extralimitaciones de los jurados mixtos, cuyas presidencias dirimentes en caso de desacuerdo entre las partes, solían recaer, según muchos, en militantes socialistas; reprueba la invasión de fincas, organizada por las "corporaciones obreras campesinas", o critica las disposiciones agrarias que vulneran las leyes precedentes. Recuerda entonces la pasividad de los socialistas durante la Dictadura de Primo de Rivera, a la que no le organizaron huelgas, y la compara con su actividad subversiva actual, con la inseguridad pública y las indisciplina de las masas, en plena República. "Vuestros actos públicos -les reprocha en una ocasión- están constantemente matizados por amenazas de toda clase; vuestros artículos en el órgano de publicidad que representa la doctrina del partido hacen lo propio". Y sobre todo se queja, como una víctima inocente e indefensa, de la injusta aversión socialista hacia él y su partido, hasta llegar al veto personal... Para llegar a la última conclusión: "Mientras estén los socialistas en el Poder, el Gobierno, aun contra su voluntad, no podrá rectificar sus orientaciones".

Le contesta el ministro Indalecio Prieto ${ }^{30}$, en un enfrentamiento oratoriamente duro, pero amable en el fondo, como ha sido el de "don Ale", su antiguo colega. El tribuno socialista le reitera que no se trata de veto, sino de incompatibilidad política, la misma que muestran a todas horas los radicales con el partido socialista. Y se enredan posteriormente en la interpretación y el sentido de la obstrucción radical en el Congreso. En su réplica, Lerroux le echa en cara a su oponente que "no pueden dominar el movimiento indisciplinado de sus masas, no suficientemente controladas". Prieto aprovecha la ocasión para contar el encargo del presidente de la República, a quien prometió no hacer declaración alguna sobre la declinación de poderes antes de hacerla ante su grupo parlamentario, y después pidió la venia al mismo presidente para una notificación pública de lo ocurrido, sin dar juicio alguno personal, como ya vimos antes. Reconoce su propósito de querer contar con el partido lerrouxista, a pesar de la previa oposición de su jefe de filas, y su fra-

\footnotetext{
${ }^{29}$ Ibidem, pp. 12-19 y 25-27.
}

${ }^{30}$ Ibid., pp. 22-24 y 26-28. 
caso posterior, porque, "hombre de partido, y a él sometido, el partido estimó que no debía requerirse la colaboración del partido radical".

Varias voces se alzaron en esa misma sesión contra el partido socialista. Sobresalió la áspera intervención del líder de la recién fundada CEDA, José María Gil Robles, todavía formalmente dentro del inicial grupo parlamentario agrario, pero ya líder indiscutido de la reciente formación política $\mathrm{CEDA}^{31}$. Gil Robles llegó a acusar a Prieto de algo que creyó interpretar torcidamente en la lectura del diario gubernamental El Sol, ocasionando un gran alboroto, interpretación que se desvaneció tras la lectura posterior del original. Pero el tono de toda la oración parlamentaria fue de alta tensión. Algunas de sus palabras fueron poco menos que "proféticas": "Intentad, si podéis, el predominio de la fuerza. Estáis fracasando en los caminos de la democracia, y nosotros esperamos muy tranquilos que fracaséis también en el de la violencia. Nosotros estamos seguros de que os hemos de vencer en vuestro propio terreno y con vuestras propias armas. Cerrad el camino a todos los partidos que pueden significar una evolución; pero como la evolución de la conciencia nacional está evolucionando, llegará un momento -lo digo con dolor- en que no solamente rebasará a los grupos moderados de la revolución, sino incluso a los mismos grupos de la derecha que no tuvieron parte en ella". Acusó asimismo a los socialistas de ser "ejecutores de la Dictadura parlamentaria", "la peor de las Dictaduras", por ser anónima, diluida en una masa, "a la cual es muy difícil exigir una responsabilidad, fuera de la que se exige en el orden de la conciencia".

Tampoco el portavoz del grupo inicial al servicio de la República, o lo que quedaba de él, Vicente Iranzo, futuro ministro, se anduvo en chiquitas ${ }^{32}$. Ellos propusieron en la consulta presidencial un Gobierno de concentración republicana. Interrumpido por parlamentarios socialistas, les espeta sus propias contradicciones de estar gobernando la República y de vituperar a la vez a la República: "Nosotros estamos oyendo constantemente (...) que los socialistas dicen: 'Esta República no es la nuestra'; 'esta República no es la que nosotros ambicionamos'. 'El partido socialista - decía el otro día una destacada personalidad del mismo- está por encima de la República'”.

El debate político continuó los días 15, 16 y 20 de junio, con intervenciones de todos los grupos y de varios diputados a título personal. Merece destacar la intervención de Francisco Largo Caballero ${ }^{33}$, sentado de nuevo en el banco azul, al contestar a Sánchez Román, que habló profusamente de muchos temas pero sobre todo de aspectos jurídicos de la legislación social y su aplicación, uno de sus temas fuertes como jurista de prestigio. El presentado como nuevo ministro de Trabajo y Previsión Social defendió la obra social durante el Gobierno anterior y la interpretación imparcial de la legislación

31 Ibid., pp. $19-22$.
${ }^{32}$ Ibid., pp. $30-33$.
${ }^{33}$ Ibid., núm. 355,16 de junio de 1933 , pp. 14-18 y $24-25$. 
hecha desde su ministerio. Tuvo tiempo también para resumir la doctrina oficial socialista, en términos moderados, sobre la división del trabajo, la existencia de las clases en la sociedad capitalista, la lucha entre las mismas, el papel del Estado en esa lucha, la acción directa, el papel de las huelgas, el de los jurados mixtos... En una réplica posterior aseguró al jurista madrileño que los presidentes de dichos jurados mixtos, nombrados por su ministerio, de tendencia socialista, no pasaban de un $10 \%$. Tampoco se mordió la lengua sobre su actuación personal: "Yo no he renunciado ni he abjurado de las teorías que me han hecho socialista; lo que hago es adaptarme a las necesidades de la República. Habrá acaso, y sin acaso, contradicción entre lo que pienso y lo que hago, pero con relación a esta contradicción quienes podrán dirigirme imputaciones y acusaciones son éstos", mientras señala los bancos del grupo socialista, donde se levantan muchos aplausos.

Cerró el debate el candidato a la presidencia del Consejo, Manuel Azaña. La votación, en la que se abstuvieron los republicanos radicales, arrojó 188 votos contra 6 . Los que votaron en contra fueron un federal y cinco agrarios, entre los que no estaba Gil Robles. No votó ningún vasco-navarro.

\section{EL CRUDO VERANO DE 1933}

Aquel verano de 1933, el peor año, en términos económicos, de la historia de la Segunda República ${ }^{34}$, la crisis económica y social llegaba a su punto más alto. La producción industrial y agrícola descendía, aumentaba el paro y se multiplicaba la conflictividad en la vida pública. El número de horas de trabajo perdidas por huelgas -sobre todo en el campo, en la construcción y en la minería - se había triplicado en comparación con el año anterior.

La reforma agraria avanzaba muy lentamente en las regiones latifundistas del Centro y del Sur, pero esa misma reforma, y dentro de ella el proyecto de ley de arrendamientos, así como varias leyes del ministerio socialista de Trabajo -ley de términos municipales, jurados mixtos...- separaban a la mayoría gubernamental, mayormente a los socialistas, de los pequeños partidos republicanos burgueses, que tenían sus afiliados y simpatizantes en la pequeña burguesía urbana y rural, sobre todo en ese Sur y en ese Centro ${ }^{35}$.

${ }^{34}$ Una síntesis de la situación general durante ese año, en la obra antes mencionada de Avilés Farré, pp. 186 y ss, y en la de TUÑÓN DE LARA, M., La II República, I, Madrid, 1976, especialmente pp. 138 y ss.

${ }^{35}$ En el Cuaderno de la Pobleta (1937) Azaña sostiene que a mediados de 1933 la tendencia "caballerista", dominante en el PSOE, ya les era "hostil". Largo fue el único ministro que no fue a su casa a despedirle cuando dejó el Gobierno. Recuerda también que en los pueblos "socialistas y republicanos andaban a la greña por cuestiones locales, ya políticas, ya de orden social. Los republicanos se quejaban de las Casas del Pueblo. Los socialistas se quejaban de los republicanos". De ahí temía él que llegara la fractura gubernamental. Y vuelve a explanar, como ya lo hizo en los diarios de 1933, sus planes de largo alcance para terminar en paz con el PSOE, a fin de que acabara siendo "un partido colaboracionista y de turno en la República”. Pese a ser aprobadas por las Cortes la ley 
No es menester añadir que muchas y variadas asociaciones de propietarios españoles, agrícolas, industriales y comerciales, más activas que nunca durantes estos meses, eran contrarias a ciertas reformas sociales de los Gobiernos de Azaña, que pretendían eliminar, a la vez que deseaban la salida de los socialistas del poder.

La Confederación Española Patronal Agrícola (CEPA), en su manifiesto fundacional de marzo de 1933, declaraba al socialismo su "enemigo: Él y sus aliados. Él y sus colaboradores, bajo disfraz político de nombres compuestos: ¡Agricultores! ¡Guerra a quien nos trajo la guerra!”36, mientras exigía la derogación de la ley de términos municipales, la libertad de contratación de la mano de obra y la modificación de la ley de jurados mixtos, a fin de evitar su intromisión en papeles propios de los poderes legislativos y judiciales.

Desde la aprobación por las Cortes Constituyentes, en 1931, de la ley de jurados mixtos, que sustituían a los comités paritarios corporativos de la Dictadura, bajo la estrecha dependencia del Gobierno, la oposición patronal fue beligerante y continua, aunque no mayor, y siempre mucho más pacífica, que la que teorizó y practicó la mayoritaria organización anarcosindicalista, Confederación Nacional del Trabajo (CNT), partidaria de la acción directa y de la huelga laboral o política como método habitual de lucha, que siempre se pasó la ley por el forro. Argumentos principales de tamaña oposición era la falta de imparcialidad del ministerio de Trabajo, en manos socialistas, a la hora de nombrar los presidentes -con voto dirimente $-\mathrm{y}$ vicepresidentes de los jurados, eligiendo entre dos ternas, si no había unanimidad entre representantes de patronos y obreros, así como las muchas facultades que se atribuían los jurados en varios ámbitos no estrictamente laborales.

A mediados de 1933 tras varias interpelaciones en la Cámara al ministro de Trabajo sobre la parcialidad y la extralimitación de los jurados mixtos, una de ellas a cargo de Sánchez Román, tuvo lugar, el día 19 de julio, en Madrid

\footnotetext{
del tribunal de garantías y del orden público, esos planes se vinieron abajo, por la atrocidad de la obstrucción, de la que culpa a Lerroux, pero también, en lo que toca a proyectos sociales como la ley de arrendamientos rústicos y del patrimonio municipal o comunal, al radical socialista Ramón Feced, notario, diputado por Teruel, y al socialista y sindicalista agrario, diputado por Jaén, Lucio Martínez Gil, que obstruyó en la comisión parlamentaria "más que todas las oposiciones juntas". Suprimiendo, como el año anterior, las vacaciones de julio y agosto, el presidente del Consejo quería alargar la vida del Congreso en orden a que el Gobierno, "con lealtad a las leyes de las Constituyentes", pudiera "ahuyentar de las imaginaciones soliviantadas el coco de la "revolución marxista" y de la "dictadura del proletariado”. Obras completas, IV..., pp. 643-646. Sobre la hostilidad entre socialistas y radical-socialistas trata igualmente Alcalá Zamora en sus Memorias..., p. 295.

${ }^{36}$ CABRERA, M., La Patronal ante la II República: Organizaciones y estrategia (1931-1936), Ed. Siglo XXI, Madrid, 1983, p 157. Sobre la cuestión agraria y la patronal durante toda la República, pp. 152-195.
} 
la Magna Asamblea Nacional de casi un millar de asociaciones patronales de toda España, que calificaron en su manifiesto final a los jurados como "instrumentos de lucha sindical, despiadada y cruel en lugar de órganos de colaboración entre los elementos esenciales de la producción", y decidieron constituir, por fin, tras variados intentos anteriores, un "órgano de enlace" entre las entidades convocantes para recoger y publicar toda la información posible sobre los jurados, pedir su reforma y tomar las medidas oportunas en caso contrario. Algunas organizaciones más extremosas, en una solicitud dirigida a las Cortes, pidieron la derogación de la ley de jurados mixtos, instrumento de partido, según ellas, para imponer o ensayar una nueva organización económica de la producción y el comercio, con influjo socialista, que en breve podía "degenerar en organización sindical". Reclamaban, además, pues la participación de los socialistas en el Gobierno había levantado un clamor unánime en todo el pueblo español que no había votado socialismo en junio de 1931, que su presencia no imprimiera "orientación de escuela" a la República $^{37}$.

En algunas de las asambleas de estas organizaciones, agrarias, industriales o comerciales, tomaron parte activa políticos de la minoría agraria, como su presidente José Martínez de Velasco o uno de sus portavoces, José María Gil Robles; radicales, como Rafael Salazar Alonso; conservadores (PPC), como Miguel Maura, o independientes, como Alfonso García Valdecasas, que había abandonado un año antes el grupo parlamentario Al servicio de la República (ASR). Todos ellos hacían responsable, de una forma u otra, a la legislación social del ministerio de Trabajo y, en general, a los Gobiernos de Azaña, de la crisis y depresión económica de España, pensamiento general, con pocas excepciones, de las organizaciones patronales españolas.

Por si todo eso no bastara, Hitler se hacía con la cancillería alemana, el 30 de enero de 1933, y los trágicos acontecimientos posteriores causaron conmoción en toda Europa, también en España, donde aparecieron o se reafirmaron los primeros grupos simpatizantes con el fascismo, sobre todo con el de Mussolini. Manuel Delgado Barreto, director del diario La Nación, órgano oficioso de la Dictadura de Primo de Rivera, logró editar, el 16 de marzo de ese año, el primer número del semanario El Fasccio, redactado por escritores como Ernesto Jiménez Caballero, Ramiro Ledesma Ramos (director en 1931 del semanario fascista La conquista del Estado), Rafael Sánchez Mazas, José Antonio Primo de Rivera o Juan Aparicio. La edición entera fue recogida y el Gobierno prohibió la publicación ulterior del periódico. Entre los días 19 y 22 de julio fueron detenidos centenares de presuntos fascistas en toda España; casi un centenar de ellos estuvieron arrestados durante una o dos semanas, pero al fin la policía se convenció de que no existía peligro alguno de subver-

${ }^{37}$ Ibidem, pp. 217-218. Sobre las organizaciones patronales de la industria y el comercio durante toda la República, pp. 196-250. 
sión fascista ${ }^{38}$. Los frentes antifascistas, promovidos en todas partes por la Internacional Comunista -que denominaba hasta entonces "social-fascistas" a los socialistas de la II Internacional-, comenzaron a organizarse también en España, propiciados por el pequeño partido comunista (PCE) y por algunos sectores del PSOE, todavía en el Gobierno ${ }^{39}$.

Son ya un lugar común, dentro de la historia de la "radicalización" del sector "caballerista", el discurso de su líder en el mitin de las Juventudes Socialistas, celebrado en el cine Pardiñas de Madrid, el 23 de julio, continuado y repetido en la Escuela Socialista de Verano, campamento de Torrelodones, organizada por la Juventud Socialista Madrileña, la más izquierdista de todas, presidida por Enrique Puente, y el giro izquierdista de las Juventudes Socialistas de España, presididas entonces por el "besteirista" José Castro Taboada (1929-1934), por influencia del equipo de la revista Renovación, dirigida por Santiago Carrillo.

Pero apenas si algún autor repara en el discurso del ministro Largo Caballero, un mes antes, en el foro internacional de Ginebra ${ }^{40}$. Habló el ministro de Trabajo y Previsión Social del Gobierno de España a los postres de la comida organizada por los delegados hispano-americanos a la Conferencia Internacional del Trabajo, en el hotel Des Berges, en la ciudad suiza. Era el tercer año que se dirigía, en tal ocasión, a tan prestigiosa audiencia, deseosa de conocer de primera mano noticias sobre la situación social de España.

El ministro español elige esta vez como tema central la conferencia económica de Londres, que por aquellos días se está celebrando, y de la que no se hace muchas ilusiones. Lo que le da pie para traer a la memoria de su oyentes las cuatro soluciones que el año anterior les propuso: la unión aduanera de Europa; una política de salarios altos y disminución de jornada, reduciéndola a cuarenta horas semanales o menos; la creación de un sistema monetario

${ }^{38}$ Sobre los débiles inicios de la Falange española y de otros grupúsculos más o menos fascistas durante 1933, PAYNE, S. G., Historia del fascismo español, Ediciones Ruedo Ibérico, París, 1974, pp. 26-46.

${ }^{39}$ Escribe Gabriel Mario de Coca, redactor de El Socialista durante la República, que la Casa del Pueblo de Madrid creó por entonces un grupo deportivo "para emplearlo como fuerza de choque y los locales obreros adoptaron precauciones contra un posible ataque estableciéndose guardias por jóvenes socialistas”. DE COCA G. M., Anticaballetro: crítica marxista de la bolchevización del partido socialista (1930-1936, Ediciones Engels, Madrid, 1936, p. 88. El autor, "besteirista" donde los hubiera, atribuye buena parte de los males de la política socialista y del propio partido, dirigido por Caballero y sus secuaces, al pecado original de la colaboración en un Gobierno burgués, a su descarado reformismo oportunista y a su olvido de los genuinos principios marxistas.

${ }^{40}$ LARGO CABALLERO, F., Obras completas, volumen V. Escritos y discursos (1933-1934). Edición a cargo de Aurelio Martín Nájera y Agustín Garrigós Fernández. Fundación Largo Caballero (Madrid)-Instituto Monsa de Ediciones (Barcelona), 2003, pp. 1730-1739. Las citas, en pp. 1730-1732. Un resumen, en El Socialista, 24 de junio de 1933. 
internacional, y una organización internacional de la emigración, a la vez que un control, del mismo rango, de los monopolios y de los empréstitos.

Otro de los temas, tocados rápidamente, de la conferencia son los "movimientos ultranacionalistas" en Europa, que según Largo Caballero, no existen en España. Pero la primera mitad de su intervención la dedica sobre todo a defender la obra de los socialistas dentro de la República española frente a sus muchos enemigos; lo que resume, dentro del ejercicio parlamentario de este año, en dos leyes capitales para el porvenir de la misma: la de la reforma agraria y la de confesiones y congregaciones religiosas.

Con la segunda de estas leyes, recalca el conferenciante, "no se persigue a la Iglesia, como se dice por ahí falsamente. Por primera vez va a haber en España verdadera libertad religiosa, sin distinción de confesiones. (...) Con esta ley se trata de limitar el enorme poder económico y espiritual que la Iglesia católica había alcanzado en España, como en otro tiempo en algunos países de América, y especialmente en Méjico, cuya evolución en muchos aspectos, y señaladamente en este eclesiástico y en el ya mencionado de la reforma agraria, tanto nos ha enseñado a los españoles". Es cierto que el presidente de la comisión constitucional, el socialista Luis Jiménez Asúa, había reconocido en las Cortes, dos años antes, la influencia de la Constitución mejicana en la española. Pero lo decían y escribían por entonces a cada paso los católicos españoles como uno de los baldones de la carta magna de 1931.

La explicación del trato dado a la Iglesia en España por el ministro español revela nítidamente la concepción que tiene del Estado republicano, y por eso me extiendo a exponerla aquí: "Un Estado que sea consciente de su misión histórica, como lo es el nuevo Estado republicano de España, no puede consentir que en el seno de la sociedad exista otro Estado tan fuerte o más que él. Por definición el Estado es un poder absoluto, está sobre todos los poderes sociales. Esa es la característica de un Estado vital, de un Estado que está a la altura de su destino. Eso quiere ser y eso será el Estado republicano español".

Siendo como es ese "poder absoluto", el Estado republicano "controlará toda la enseñanza, para que el alma de las nuevas generaciones no se deformada por doctrinas contrarias al Estado republicano y a los principios de nuestra Constitución republicana". Y junto a su concepto de Estado, he aquí su concepto de la libertad que nos evoca directamente la célebre pregunta de Lenin al colega de Largo en el gabinete, el socialista granadino Fernando de los Ríos, enviado a Moscú, a finales de 1920: "La libertad absoluta de enseñanza, como cualquier forma de libertad absoluta, es incompatible con todo Estado creador. ¿Libertad para qué?, se pregunta todo auténtico hombre de Estado. ¿Libertad para socavar los cimientos del Estado y demolerlo en la primera ocasión propicia? Sería una ingenuidad que los verdaderos republicanos y socialistas no estamos disgustos a cometer".

Ya reconoce el tribuno marxista que este concepto y ejercicio del Estado "no puede agradar a los poderes históricos vencidos: a los residuos monárquicos; a la aristocracia feudal y latifundista; a la oligarquía eclesiástica; al 
militarismo; al caciquismo local. Tampoco agrada a los anarcosindicalistas, enemigos de todo Estado y de toda ley, mentes infantilmente utópicas, que no acaban de comprender el carácter evolutivo de las sociedades humanas". Todos ellos se han estrellado, en enero y en agosto pasados, y se estrellarán cuantas veces lo intenten, no sólo por la fuerza intrínseca del mismo Estado, que es invencible, sino por el apoyo casi unánime de la nación y por las reservas incontrastables que representan el Partido Socialista y la Unión General de Trabajadores.

Y aquí el exconsejero de Estado de la Dictadura y el ministro reformista del primer bienio republicano duda de si hicieron bien en "transigir con una ideología liberal y democrática que pertenece a otros partidos republicanos, pero que no es esencialmente la nuestra, la del Partido Socialista", anteponiendo a todo una Constitución liberal y no "legislando por decreto, sin trabas parlamentarias, durante cuatro o seis años, radicalmente y con rapidez, creando un Estado de hecho revolucionario" 41 .

Olvidándose en Ginebra de que es ministro de un Gobierno constitucional y, ahora y después, de que sus diputados a Cortes no pasaron de 115 en el mejor momento, repetirá esta misma duda, o remordimiento tal vez, en sus discursos electorales por el centro y sur de España, y hasta lo considerará uno de los grande errores de la "República burguesa=dictadura burguesa", que los socialistas, tanto como cualquiera, colaboraron a implantar.

En el cine Pardiñas - propiedad del madrileño Tomás Álvarez Angulo, diputado socialista por Jaén-, 23 de julio de 1933, al que se accede "por rigurosa invitación", e invitado por las Juventudes Socialistas de Madrid, comienza Largo, todavía ministro de Trabajo y Previsión Social, trazando su propia biografía sindical y política para hacer luego un repaso sobre la participación socialista en los Gobiernos de la República, desde los tiempos del comité revolucionario ${ }^{42}$. Tras afirmar que ellos tienen el mismo derecho que los demás a gobernar el país, entra en el meollo del discurso, que va a ser el

${ }^{41}$ La conquista del poder y el Estado socialista no eran cosas sólo de Largo Caballero y de sus seguidores más cercanos, que eran muchos, ni sólo algo que se les ocurriera a comienzos o mediados de 1933. Recuérdese el tercer punto de la ponencia sobre "Problemas tácticos", en el citado XIII Congreso del PSOE, del año anterior a la que arriba me he referido, que habla explícitamente de "una acción netamente anticapitalista, independiente de todo compromiso con las fuerzas burguesas" y de "la conquista plena del poder para la realización del Socialismo". El Socialista, 13 de octubre de 1933.

${ }^{42}$ Obras completas, V..., pp. 1752-1792; El Socialista, 25 de julio de 1933, llena casi las tres primeras páginas con la transcripción taquigráfica del discurso. "Hemos contribuido - dice el epígrafe a cinco columnas- a la transformación para hacer un Código que nos permita llegar a nuestras aspiraciones sin violencia". El editorial, que se titula "Ponderación y firmeza", resalta la claridad del discurso en el instante en que el partido que Largo preside "sufre la embestida más brutal, más torpe y más bellaca de que guardan memoria los viejos socialistas". En la sustanciosa pieza oratoria "no sobra nada pero nada falta". 
de todos sus discursos posteriores: "la conquista del poder". Colaboraron seriamente los socialistas españoles para hacer una "Constitución flexible", susceptible de que un partido revolucionario como el suyo, "que quiere hacer una transformación de la sociedad en absoluto, socializando los medios de producción, lo pueda hacer con arreglo a sus preceptos y sus leyes, y que les permita poder cumplir sus aspiraciones, sin violencias grandes, sin grandes derramamientos de sangre". Pero, si, por ser socialistas, no pueden gobernar, si no les permiten conquistar el poder con arreglo a la Constitución y con arreglo a las leyes, se encrespa el orador, "tendremos que conquistarlo de otra manera" 43 .

Una formidable ovación y continuas vivas al tribuno se repiten entusiásticas. Más adelante habla de la situación europea. En ningún país, en cuyos Gobiernos participaron los socialistas, surgió el fascismo ni la dictadura. Pero en Italia y Alemania sí pueden implantarse, pero sólo "porque el régimen capitalista está en el período e mayores dificultades y juega sus últimas cartas, y se defenderá con la dictadura burguesa para someter violentamente a toda las clase obrera descontenta y echar la responsabilidad de todos los males al marxismo...". Ante eso, el PSOE y la UGT “tienen la obligación, el deber,

${ }^{43}$ Suelen los autores especialistas en este período coincidir en que el fin del "posibilismo socialista" y el giro hacia la ideología y la práctica bolchevique dentro de buena parte del PSOE y de la UGT a partir de 1933 se deben sobre todo al sentimiento de frustración tras los años de colaboración gubernamental y el fracaso de algunas reformas sociales promovidas por los gobiernos de Azaña; a la amenaza por parte de la derecha económica y política de anular tales reformas, junto al miedo ante el fascismo ya gobernante en Alemania e Italia y creciente en todas partes, y a la incapacidad del socialismo español para pensar en términos de estrategia su propio reformismo, lo que les llevó a una huída hacia adelante. Así BIZCARRONDO, M., que conoce bien este mundo, en su Historia de la UGT: Entre la democracia y la revolución, III, Ed. Siglo XXI, Madrid, 2007, especialmente pp. 81-100. Ya desde febrero de 1933, las publicaciones ugetistas se interesaron por la marcha del fascismo -así se llamaba habitualmente al nazismo- en Alemania, producido en el caldo de cultivo de la exacerbada protesta nacionalista y del afán de venganza contra los países responsables del Tratado de Versalles, a quienes atribuían todos los males del país, incluida la crisis económica y el paro alarmante. La Unión General de Trabajadores comenzó a organizar desde entonces la solidaridad con los perseguidos sindicatos alemanes por medio de colectas entre sus afiliados y simpatizantes así como de actos de propaganda.- Niceto Alcalá Zamora, en su asendereado libro de memorias, si bien reconoce la decisiva influencia que tuvo el triunfo del nazismo alemán sobre el socialismo europeo, atribuye también el giro político de Caballero en particular, a una grave enfermedad, con insomnios constantes: "fue Largo otro hombre muy distinto del que había sido". Y recuerda aquella su "mirada de ira y fiereza, inmediatamente reprimida. Lo cierto es -continúa- que pasó al inadecuado y funesto papel de Lenin español el hombre que había sentido antes reciprocidad intensa de odios respecto del comunismo, el que en el cárcel se exaltaba más que nadie contra toda idea de promiscuidad que se opusiera en la familia a las seguras y apartadas relaciones de hogar, y sostenía resueltamente que no había entendido a Marx quien negase la propiedad de lo ganado por el trabajo y el derecho de transmitirlo a los hijos". Memorias..., p. 294. 
aunque les cueste algo caro, de impedir una dictadura burguesa, de oponerse al desarrollo fascista de la República". Y dice algo más: "No es que queramos nosotros implantar la dictadura nuestra caprichosamente, sino que, si hay quien tiene el mal pensamiento de implantar en España una dictadura burguesa o el fascismo, nosotros preferimos la dictadura socialista". Enorme ovación. Lo repite, un rato más tarde: "Que conste bien: el Partido Socialista va a la conquista del Poder, y va a la conquista, como digo, legalmente si puede ser. Nosotros deseamos que pueda ser legalmente, con arreglo a la Constitución, y, si no, como podamos. Y, cuando eso ocurra, se gobernará como las circunstancias y las condiciones del país lo permitan" (Muy bien). "Lo que yo confieso es que, si se gana la batalla en unas elecciones, no podemos entregar el Poder al enemigo" 44 .

Explica después detallada y muy elogiosamente toda la legislación social del primer bienio republicano, para aconsejar finalmente a los jóvenes y a todos "unión, disciplina, voluntad". Tras una "ovación delirante", el presidente de Juventudes Socialistas de Madrid, Enrique Puente, dice unas palabras de agradecimiento, y se cierra el mitin con el canto de la Internacional y el himno de la Juventud.

En la Escuela Socialista de verano, en Torrelodones, hablaron ante dos centenares de jóvenes durante los meses de julio y de agosto más de una veintena de dirigentes del partido, mayormente diputados, sobre los muy diversos temas de su especialidad. Los días 5 y 6 , respectivamente, les tocó el turno a Besteiro $^{45}$ y Prieto. A Julián Besteiro ya le había dicho unos de los asistentes que, los días anteriores, se había hablado en el campamento mucho de democracia y de dictadura, sobre todo de dictadura ${ }^{46}$. El todavía presidente de las Cortes Constituyentes hace un breve recorrido por la historia del socialismo -socialismo filantrópico, anarquista, científico...-, critica el nacionalismo socialista durante la primera guerra mundial, carga la mano contra

${ }^{44}$ Cuenta Vidarte que, mientras se discutía en las Cortes la ley electoral, aprobada el 27 de julio, y que iba a modificar mínimamente el decreto del 8 de mayo de 1931, en una reunión informal de varios miembros de la CE en una secretaría de las Cortes (probablemente en la suya), a petición de Fernando de los Ríos, planteó Largo ir a las próximas elecciones "en un bloque formado por todos los partidos proletarios". Los tres ministros presentes y los otros dirigentes, de los que no se nos da noticia quedaron en forjar un criterio común junto con el comité nacional y pedir opinión a las agrupaciones. Allí ya hablaron de ir solos a las elecciones próximas. Las Cortes Constituyentes..., pp. 618-620.

${ }^{45}$ BESTEIRO, J., Obras completas, III, Ed. Centro de Estudios Constitucionales, Madrid, 1983, pp. 73-98. Sobre Julián Besteiro en este tiempo, LAMO DE ESPINOSA, E.CONTRERAS, M., Politica y filosofia en Julián Besteiro, Ed. Sistema, Madrid, 1990, pp. 89-96.

${ }^{46}$ Sobre la invitación de la Juventud Socialista de Madrid a Besteiro, a través de Santiago Carrillo, y la correspondencia con éste, ver en la Fundación Pablo Iglesias el Archivo de Julián Besteiro: AJB 234-66. 
el socialismo de Estado y la dictadura leninista ${ }^{47}$, contra todas las dictaduras europeas contra-revolucionarias, así como contra el nacional-socialismo alemán, hasta llegar a la situación española. Tras citar a Otto Bauer, el hombre de "espíritu más revolucionario" del tiempo, en favor de la democracia, "que nos ofrece condiciones permanentes y una actividad verdaderamente fecunda", arremete contra toda dictadura: incluida la dictadura de los economistas anglosajones: “¿Es que habrá posibilidad de salir de esta locura dictatorial, que invade el mundo? Porque ahora todo el mundo quiere ser dictador y por eso precisamente debemos prevenirnos (...) ¿Es que nos vamos a dejar atrapar de la peste del momento? ¿O es que somos hombres que tenemos una concepción de nuestra vida, de nuestro método, de nuestro sistema, que nos hace inmunes a los contagios de esos caprichos?". Para el catedrático de lógica de la universidad central, ex presidente del partido y actual presidente de la UGT, el valor revolucionario del PSOE es ser fieles a los principios en medio de esta ola de enloquecimiento burgués o de proletarios que todavía tienen pegado el cascarón en la mitad de su cuerpo o en la mitad de su espíritu y no se ha podido desprender de él.

Conocedor de Marx como es, y de irrenunciable profesión marxista, tiene interés en subrayar al final de su alocución que "ser revolucionario" para el fundador del marxismo no es tarea fácil y que para ello hay que trabajar mucho, sufrir mucho, estudiar mucho, meditar mucho: muchas veces "se es más revolucionario resistiendo una de estas locuras colectivas que, dejándose arrastrar por ellas, dejándose llevar por la corriente de las masas para cosechar triunfos próximos y aplausos seguros, a riesgo de que después sean las masas las que cosechen los desengaños y los sufrimientos".

La acogida del público juvenil fue, como era de temer, muy fría ante este inesperado rapapolvos del socialista más conocido en España, y El Socialista,

${ }^{47}$ En el homenaje rendido, el 2 de julio de 1933, al líder minero y ex diputado a Cortes por Oviedo, Manuel Llaneza Zapico, en Mieres, donde murió en enero de 1931, Besteiro, entonces presidente de las Cortes Constituyentes y presidente de UGT, expuso abierta y ampliamente sus anteriores discrepancias con otros compañeros de su partido -no participación en el poder, Senado o Cámara de intereses...- y también sus señas de identidad marxista democrática, no reformista ni oportunista. Hablando de la proclividad de algunos en aquel tiempo hacia posiciones bolchevistas y soviéticas, saltando por encima de las condiciones de una República democrática, se preguntaba con ciertas puntas de ironía: "Y yo digo: ¡Bueno! Que nos hemos todos bolcheviques. Pero ¿para eso hemos estado tanto tiempo luchando con el partido comunista español? ¿Y para eso murieron algunos de nuestros compañeros luchando con los comunistas? ¿Y para eso un compañero nuestro fue asesinado en la Casa del Pueblo? ¿Para acabar siendo bolcheviques nosotros? Ah, no, no”. Opuesto a la dictadura soviética militarista leninista, dictadura en el sentido clásico de la palabra", aclaraba qué quería decir Marx cuando hablaba de dictadura: "Quería decir el Gobierno de una clase obtenido por procedimientos democráticos. De modo que Marx, si en las elecciones vencía a los partidos burgueses, sólo gobernaría en nombre de una clase, ejerciendo una dictadura sobre la clase sometida: la del proletariado". 
dirigido desde primeros de marzo por el periodista vasco Julián Zugazagoitia, diputado entonces por Badajoz, ni siquiera dio noticia de su intervención ${ }^{48}$.

Prieto, en una intervención con puntas literarias ${ }^{49}$, presume largamente de la obra de los socialistas en la República, que nos les ha decepcionado, porque tampoco pusieron en ella "ilusiones pueriles"; y los que creyeron que con la República se ha había abatido para siempre a las fuerzas de la derecha "estaban equivocadísimos"; adormecidas, anonadadas, acobardadas, van recobrando su brío, y son fuerzas potentes, "con toda la energía de una tradición secular, que no se abatieron por el simple hecho de trocar el régimen monárquico en régimen republicano".

Pondera el papel insustituible del PSOE en la consolidación del régimen, pero, aunque un día pudieran recoger en medio de la calle el poder político, sería una desgracia: "y las desgracias no se aceptan voluntariamente, se admiten como cosa fatal, ineludible, muchas veces vinculadas a estrictos deberes de la ciudadanía" En este momento se oyen las primeras aclamaciones: "Muy bien. Muy bien". Y ¿por qué dice esto? Porque "habría forzosamente que gobernar en burgués". Y, aunque su reino sí es de este mundo, dice parafraseando la cita evangélica, "nuestro reino, por lo que respecta a España no es de este instante". Niega la analogía entre las circunstancias de la Rusia revolucionaria y las de España de 1933, y da por seguro que ante una acometida de las naciones de régimen burgués, idéntica a la que padeció Rusia, una España plenamente socialista "perecería asfixiada" 50 .

48 "La alternativa que Besteiro representaba era en esencia una abstracción ideal, que sólo puede apreciarse retrospectivamente, no un programa de acción", escribe críticamente el historiador de este período, Edward Malefakis en el prólogo a la edición, preparada por él, de PRIETO, I., Discursos Fundamentales, Madrid, 1975, pp 9-10. Según G. Mario de Coca, los jóvenes de la Escuela de Verano contestaron a la ponderada exposición de Besteiro "con muestras ostensibles de desagrado, expresando adecuadamente su incompatibilidad". Anticaballero..., p. 101.

${ }^{49}$ Discursos fundamentales..., pp. 160-180; también El Liberal, de Bilbao, 9 de agosto de 1933. El comentario del mismo autor en PRIETO, I., Convulsiones en España: Pequeños detalles de grandes sucesos, III, Ediciones Oasis, México, 1969, pp. 160-163.

${ }^{50}$ El 11 de febrero -fecha de la proclamación de la I República- de 1933, se creó en Madrid la Asociación de Amigos de la Unión Soviética, que ya existía en países como Estados Unidos de América, Inglaterra, Alemania o Japón. En un breve manifiesto consideran sus fundadores que la creación de la República obrera rusa (sic) es el acontecimiento económico y social más formidable del mundo moderno, y declaran que no tienen otro programa ni otra bandera que decir y ayudar a conocer la verdad sobre la URSS, combatiendo con las armas de la verdad la mentira, la calumnia y la deformación. Entre sus firmantes, encontramos intelectuales y escritores, como Valle-Inclán, Baroja, Benavente, Concha Espina, Marañón, Manuel Machado, María Martínez Sierra, García Lorca, Sender...; científicos, como Pío del Río Hortega, Juan Negrín, Teófilo Hernando, Marcelino Pascua, Gordón Ordás...; economistas, como Agustín Viñuales; juristas, como Sánchez Román, Wenceslao Roces, Clara Campoamor, Victoria Kent, Jiménez de Asúa, Augusto Barcia, Rafael Salazar Alonso, Diego Hidalgo, Eduardo Barriobero, José Antonio Balbontín...; artistas, como Ricardo Baroja, Regino. Sainz de la Maza, Nicanor Piñole, Luis Bagaría, 
Concede de buen grado el ministro socialista vasco que la juventud está mucho más preparada y era mucho más libre y crítica que la de antes. Él no quiere apagar las llamas de ningún ideal, pero sí quiere pedirles a sus jóvenes oyentes, sentados al aire libre, un poco de atención para los consejos de algunos de sus mayores: "Pero, si oís voces menos ardorosas, sin apóstrofes tribunicios para conducir a las gentes a la pelea; si hombres de edad más avanzada que la vuestra suben a la tribuna a pediros cordura, para llamaros la atención sobre el exceso de vuestro ímpetu, no será mucho exigiros un gesto de simpatía y de respeto para quienes, caminando delante de vosotros, os abrieron holgadamente el camino por donde ahora marcháis (Muy bien)".

Tras la constitución política de nuestro país, hay que "constituir económicamente a España". Y el ministro de Obras Públicas pone atención sobre todo en la transformación del campo por medio de las obras hidráulicas "asegurando el pan de todo el año a míseras legiones de campesinos que comen a temporadas".

Apela finalmente a una "maravillosa unión" del partido socialista, sobre todo cuando haya de apartarse del poder; a una unión integral de palabra y corazón que les dé fuerza para ejecutar los propios designios: “¿Sabéis cuál es el nuestro, el fundamental ahora? El de mantener nuestra unión para aplicar su fuerza, cuando el caso llegue, como mejor convenga al partido socialista, y con él al proletariado de España y del mundo entero (Grandes aplausos)" ${ }^{\prime \prime}$.

\footnotetext{
Victorio Macho...; periodistas, como Luis Bello, Julián Zugazagoitia, Roberto Castrovido, Ezequiel Endériz, Luis de Tapia... Políticos muy conocidos están en estas filas de amigos de la URSS; socialistas como Negrín, Jiménez de Asúa, Marcelino Pascua, Zugazagoitia, Rodolfo Llopis, Amaro del Rosal; republicanos radicales, como Campoamor, Hidalgo, Salazar Alonso; radical-socialistas, como Gordón y Kent; azañistas (AR), como Barcia y Viñuales; federales, como Barriobero y Rodrigo Soriano; comunistas, como Balbontín. De todos ellos, merece destacarse el asturiano Wenceslao Roces, que estudió en Madrid y también en Alemania, becado por la Junta de Ampliación de Estudios; catedrático de instituciones pública en la universidad de Salamanca, fue expulsado de su cátedra por la Dictadura; miembro del PCE; cofundador de la editorial Cenit, para la cual tradujo buena parte de las más importantes obras de autores marxistas, desde Marx a Rosa Luxemburgo, en la Biblioteca Carlos Marx. - La oficina de la Asociación fue asaltada el día 14 de julio de ese año por tres pistoleros jonsistas (Juntas de Ofensiva Nacional Sindicalista (JONS), de carácter fascista, formadas en 1931 por el grupo de Ramiro Ledesma Ramos, fundador de la revista La conquista del Estado, y por las Juntas Castellanas de Actuación Hispánica, de Onésimo Redondo. Loa asaltantes maniataron al directivo de turno, W. Roces, y al empleado de la oficina, les destrozaron el teléfono y se incautaron de las fichas de los centros y de los "amigos" en toda España, llevándose las llaves y dejándolos encerrados. $A B C, 15$ de julio de 1933.- El día 27 de ese mismo mes, firmó el Gobierno español el reconocimiento oficial del régimen soviético, acogido por parte de la prensa derechista española con alarmada inquietud.

${ }^{51}$ Edward Malefakis, editor y prologuista del libro citado, alude a la convicción de Prieto, expresada en este discurso, de que una victoria del socialismo en España no valdría la pena ni para la República ni para el partido por los costes específicos que supondría y las consecuencias que engendraría. Y comenta: "Esta ambigüedad en el pensamiento de
} 
El mismo Prieto recuerda, muchos años después, que el auditorio juvenil le oyó "con notoria displicencia". Tampoco el órgano del partido recogió el discurso en sus páginas. Pero, como hemos visto, la displicencia no parece haber sido tanta. Claro que Prieto, excelente orador parlamentario y de masas, estaba acostumbrado a triunfales acogidas populares.

\section{DENTRO Y FUERA DEL GOBIERNO}

Los jóvenes socialistas llamaron entonces al presidente del partido para que les llenara el vacío. En la conferencia sobre "Posibilismo socialista en la democracia", el siguiente día 12, apenas comienza a hablar, Largo se muestra convencido de que "realizar obra socialista dentro de una democracia burguesa es imposible"; se oye entonces gritar "Muy bien". Lo cierto, dice poco más tarde, es que él, que tenía fama de hombre "conservador y reformista", cuando lo que era en realidad era "intervencionista" en el sistema capitalista, tras pasar por el Gobierno, saldrá "mucho más rojo" que entró, "ipero mucho más!". Después, citando a Marx en el Programa de Gotha, juzga inevitable "la dictadura del proletariado en España", dado el carácter del capitalismo en nuestro país, aunque sin tener que imitar a Rusia, cuya revolución justifica, "ya que las circunstancias nos van conduciendo a una situación muy parecida a los que los rusos se encontraron", contradiciendo directamente así a lo sostenido por Prieto. Y repite, fundamentalmente, con similares palabras, aunque menos enfática y retóricamente, los conceptos vertidos en el cine Pardiñas. Los jóvenes socialistas le aplaudieron a rabiar, entusiasmados ${ }^{52}$.

Semanas más tarde, el presidente FLC da unas respuestas breves pero contundentes a las preguntas muy intencionadas de Santiago Carrillo, hijo de Wenceslao, secretario de actas de la comisión ejecutiva de las Juventudes Socialistas desde el congreso de febrero de 1932, y director del semanario Re-

Prieto debilitó su posición e hizo mucho más fácil para el PSOE el adoptar, en contra de sus deseos, la decisión crítica de abandonar la alianza electoral con los republicanos de izquierdas, lo que a su vez contribuyó a acrecentar las desastrosas dimensiones de la derrota sufrida por toda la izquierda en las elecciones de noviembre de 1933". Prólogo a PRIETO, I., Discursos fundamentales, Ed.. Turner, Madrid, 1975, p 23. De Coca dice que a Prieto, "que tuvo mejor fortuna", al terminar el discurso, algunos de sus oyentes le dirigieron frases intencionadas. Uno le echó en cara el no haber anulado el leonino contrato con la Compañía Telefónica norteamericana, por miedo a una guerra con los Estados Unidos, cuando desde el Ateneo de Madrid, en tiempos de Berenguer, él mismo había denunciado duramente el "inconcebible acto de rapiña" llevado a cabo por el dictador Primo de Rivera. Anticaballero..., p. 101.

${ }^{52}$ Obras completas... pp. 1794-1848. Esta vez sí aparece en El Socialista del día 13, p. 4, en cuatro columnas centrales, un extracto de la conferencia de Caballero. Dicen títulos y subtítulos: "El presidente del Partido diserta ante los jóvenes becarios de los problemas de nuestro movimiento. Saldré del Gobierno más socialista que cuando entré. Confianza en la capacidad de los trabajadores. Necesidad de trabajar por la victoria de nuestra causa. Preparación para merecerla". 
novación, que las recoge en su número110, del 23 de septiembre, y las transcribe a su vez El Socialista del 24. En ellas el líder marxista revolucionario responde que los compromisos con los partidos republicanos "se han liquidado" y que para el futuro "habrá que pensar mucho antes de convenir ninguno". Afirma luego que el partido socialista no se diferencia del comunista "doctrinalmente en nada, y que les separa más que otra cosa el deseo de un partido nuevo (...) de suplantar en la lucha a otro partido -el nuestro-, que ha conseguido encarnar las aspiraciones de la clase obrera". Respondiendo a la cuestión candente entonces en una facción del PSOE, especialmente en sus Juventudes, asegura que "el capitalismo acudirá a la violencia máxima para mantener sus posiciones, y el Socialismo tendrá que llegar también a la violencia máxima para desplazarle". Para anunciar seguidamente: "Estamos a las puertas de una acción de tal naturaleza, que conduzca al proletariado a la revolución social". Y comenta Carrillo, que ha convertido en subtítulos clamorosos las resonantes declaraciones del presidente: "La palabra de Largo es enérgica y serena" 53 .

El pensamiento revolucionario de muchos jóvenes socialistas venía ya de atrás. Entre las resoluciones del IV Congreso nacional de las Juventudes

${ }^{53}$ El equipo redactor de Renovación, dirigido por el periodista Santiago Carrillo, redactor de El Socialista desde 1930 estaba compuesto por Carlos Hernández Zancajo, José Cazorla, José Laín, Federico Melchor, Serrano Poncela..., todos jóvenes valores, que después de unos meses iban a hacerse con la dirección de Juventudes y la mayoría de los cuales pasará dentro de pocos años al partido comunista. Carrillo, en su libro de memorias, da un precioso testimonio del cambio ideológico-político operado durante esos meses en la juventud socialista y en buena parte del partido y hasta de la sociedad española, y nos indica sus fuentes de inspiración: "Entre los jóvenes socialistas - escribe- se han producido cambios. El equipo de izquierda constituido en torno a Renovación se ha convertido de hecho en el dirigente de la organización juvenil; la mayoría de derecha de la Comisión Ejecutiva elegida en 1932, se ha dispersado. La tirada y venta del semanario ha ido creciendo y en el año 1934 llegaría por encima de los 40.000 ejemplares, lo que para aquel momento es un éxito. En la práctica no sólo dirigimos la Juventud Socialista, ejercimos una indudable influencia en el interior del PSOE. Cada vez más aparecemos identificados con Largo Caballero, que pronto comenzará a hablar de revolución, de la conquista del poder y de la dictadura del proletariado. El ejemplo de la Unión Soviética es una fuente de inspiración, incluso antes de que tengamos ninguna relación con el Partido Comunista de España". Insiste en la influencia que la ideología, "que tiene su espíritu en la URSS", va ejerciendo no sólo en el socialismo español, sino en todos los movimientos juveniles de la época. Sobre el temor al fascismo, que aglutinaba en esa época a la izquierda y la mantenía a todas horas alerta, escribe Carrillo: "La experiencia que vivíamos en Europa era que la democracia, traicionada por los políticos burgueses, era impotente frente a al avance del fascismo. Y se trataba de una batalla a vida o muerte. Donde ganaba el fascismo, se condenaba a la horca o al hacha a los militantes obreros, eran aplastadas sus organizaciones. No se trataba de simples cambios de gobierno, sino del ser o no ser, de la vida o la muerte, de la libertad o la tiranía. Los jóvenes socialistas llegaron a perder la confianza en la democracia burguesa: muchos de nuestros mayores, con Largo Caballero a la cabeza, también la habían perdido". CARRILLO, S., Memorias, Ed. Planeta, Barcelona, 1994, pp. 80-81. 
Socialistas, febrero de $1932^{54}$, hay dos de ellas que merecen una reposada atención. La primera se titula "Milicias Socialistas" 55 , y como dicen sus anónimos autores, al disponer de poco tiempo para hacer un dictamen extenso, se limitaron a exponer unas cuantas razones y cinco breves normas prácticas para llevar a cabo lo planteado. Comienzan diciendo que "España necesita consolidar de manera definitiva la República instaurada". De los elementos extremistas, tanto de las derecha como de la izquierda, parten golpes traicioneros contra ella y de las dos fracciones, pero con dinero de la misma procedencia, se organizan toda clase de ataques: "La defensa de la República no puede estar a merced de gente pagada, que un día defiende un criterio y al día siguiente el más opuesto al anterior". "Las Milicias Socialistas -se dice en la parte expositiva-, más que el órgano para hacer la revolución, sin que esto lo desdeñemos, han de consistir en el pueblo armado para sostener el régimen socialista. Si por un acontecimiento imprevisto el Poder viniera a manos del Partido Socialista, no podemos correr el riesgo de encargar su custodia a la guardia civil o a otra fuerza mercenaria. Serán los jóvenes socialistas los encargados de esta misión, para lo cual deben tener sus Milicias preparadas".

Muy relacionada con la anterior estaba la resolución sobre "las Juventudes ante la evolución del Socialismo" 56 . Los anónimos militantes juveniles designados para informar sobre la ponencia del mismo título preparada por la comisión ejecutiva la consideran "vaga e imprecisa" y someten un nuevo texto a la aprobación del Congreso. Considerando que el "proceso de descomposición capitalista toca a su fin"; que se recrudecen los ataques de los enemigos del bando conservador y del bando extremista, y que la revolución llevada a cabo en España puso al descubierto "el antagonismo de clases existente y la pugna entre la democracia burguesa" y lo que ellos entienden por "democracia obrera, en su más amplio y elevado sentido antiburgués y marxista", formula las siguientes proposiciones:

$1^{\text {a }}$. Se adhieren incondicionalmente al PSOE, del que las Juventudes Socialistas se consideran "leales aliados y colaboradores", y cuya actitud frente a la monarquía y a favor de la República ven con simpatía.

$2^{\mathrm{a}}$. Entienden que la consolidación del régimen republicano está íntimamente relacionado con la parte social del programa legislativo de las actuales Cortes: reforma agraria, control obrero, paro forzoso...

$3^{\mathrm{a}}$. Piensan que, una vez disueltas las Cortes, el partido no debe aceptar la colaboración directa o indirecta "con ningún partido ni Gobierno burgués, por democrático que se llame, asumiendo únicamente el Poder, si el Partido dispusiese de aquellos medios precisos que garanticen la realización de un programa afín con nuestros principios".

${ }^{54}$ Federación de Juventudes Socialistas. Resoluciones del IV Congreso Nacional, Ed. Gráfica Socialista, Madrid, febrero 1932.

${ }^{55}$ Ibidem, pp. 22-25.

${ }^{56}$ Ibid., pp. 28-31. 
4a. Supuesto ese poder socialista, y en caso de resistencia por parte de la "democracia burguesa" que imposibilite llevar a cabo su programa del partido, "se vaya directamente a la conquista del Poder por la acción revolucionaria de masas".

$5^{\text {a }}$. Para establecer gobiernos socialistas sólidos se hace imprescindible que el partido, las juventudes y los sindicatos afines "formen y adiestren organismos propios que puedan convertirse en cualquier momento en instituciones adaptables al sistema de gobierno y reemplazar con ventaja a otros organismos políticos creados por el régimen burgués y que no tienen posible utilización en las normas de un Gobierno socialista".

$6^{\mathrm{a}}$. El sostenimiento de un Gobierno socialista ha de basarse "en una inteligente y disciplinada agrupación de fuerzas exclusivamente obreras, tanto nacional como internacionalmente", para lo cual se hace imprescindible una más activa intervención del partido cerca de la Internacional Obrera y Socialista, "para que acelere el ritmo de los acontecimientos que hagan factible el triunfo internacional y definitivo del Socialismo" 57.

Sin embargo, en lo que atañe a las relaciones con comunistas y sindicalistas, todavía las reservas son muy grandes. Una circular sobre este delicado punto, publicada en 1932, sin que se indique la fecha, mandaba no aceptar los requerimientos para cualquier controversia pública ni organizar "actos con otros elementos, conforme determinan nuestros propios estatutos" 58 .

Aunque no sea éste el lugar para demorarnos en la ideología de la fuerza política opuesta al socialismo en la España de entonces, una sucinta consideración sobre el epicentro del bloque antimarxista, que tendrá su expresión más vibrante en las candidaturas conjuntas para las elecciones de fin de año, nos ayudará a sopesar mejor lo que acabamos de leer y lo que iremos leyendo en las próximas páginas, aun antes de llegar a la campaña propiamente electoral.

${ }^{57}$ Cuál fue el cumplimiento de estas dos resoluciones dentro del partido socialista nos lo dice implícitamente la proposición de la Juventud Socialista de Madrid, la más activa y fronteriza, presentada al siguiente congreso de 1934: "No dudamos que es la ponencia de "Milicias Socialistas" la que más dificultades encontró y ha de encontrar para ser llevada a la práctica; pero esperamos que la Ejecutiva no desmayará ni un solo momento hasta que plasme en una realidad esta ponencia. (...) Lo que sí quiere esta Juventud es que se ratifique en el acuerdo del anterior" Y en cuanto a la ponencia "Evolución del Socialismo", relacionada con la anterior, la misma proposición considera que, "al creer que por los medios evolutivos no hemos de conseguir este objetivo [la conquista del poder político], procedamos a la formación de los organismos adecuados para abatir al capitalismo y que, a la vez, sean instrumentos de defensa del régimen que preconizamos". Federación de Juventudes Socialistas. Memoria del V Congreso. Ed. Gráfica Socialista, Madrid, 1934, pp. 107108.

${ }^{58} \mathrm{Ibidem}, \mathrm{pp} .67-68$. En Antequera llegaron a expulsar a un compañero que, trabajando en la imprenta, había publicado en el periódico socialista local La Razón un llamamiento "de tipo comunista", Ibid., pp. 68-69. 
Ya desde el 29 de abril de 1931, la asociación, luego partido, Acción Nacional, y después Acción Popular (marzo de 1932), fundado por el joven abogado y periodista Ángel Herrera, fundador y director del diario El Debate desde 1911, fue decisivo dentro del catolicismo político español por su cohesión, su extensión y su fuerza ideológica. Mucho más después de la creación de la CEDA (Confederación Española de Derechas Autónomas), en marzo de 1933. No había nada igual en toda España, ni en volumen ni en organización, que pudiera oponerse al frente socialista-marxista (PSOE-UGT) como este conjunto católico-conservador-antimarxista. Tenía un líder joven, capaz e indiscutible, José María Gil-Robles, que sucedió al abogado y priodista Ángel Herrera el 19 de octubre de 1931, y un diario prestigioso en Madrid, El Debate, dirigido por Herrera hasta febrero de 1933, formidable centro de unidad de pensamiento y de acción de los católicos españoles que se enfrentaban al nuevo régimen laicista con voluntad de revisión constitucional pero por medios legales, en torno a los lemas sagrados de religión, patria, orden, familia, trabajo y propiedad. El Debate; el $A B C$, diario monárquico conservador por excelencia, y, en mucho menor medida, El Siglo Futuro, clásico órgano integrista, y supremo carlista desde comienzos de 1932, eran los tres voceros más importantes de la derecha católica española, en tres tonos distintos, es cierto, pero con algunos signos, lemas y sobre todo principios teológico-políticos harto similares.

Tomando pie en el último discurso pronunciado por el director de $E l \mathrm{De}$ bate en el teatro de la Zarzuela de Madrid, el 5 de febrero de 1933 -tres días antes de que dejara la dirección del diario para presidir la Junta Central de Acción Católica- y en otros muchos escritos del mismo diario, el profesor Antonio Elorza habla de la visión "donosiana", maniquea y deformadora, que tiene este inspirador e impulsor de la derecha católica acerca de los conflictos políticos y morales, que caracteriza la coyuntura histórica española como "enfrentamiento teológico de las fuerzas del Bien y del Mal ante el que no cabía neutralidad alguna" 59 .

Ya antes de las elecciones de abril de 1931, pero sobre todo tras los incendios de iglesias y conventos, este carácter contra-revolucionario, esta visión del combate entre dos civilizaciones, la cristiana y la comunista-socialista se va extendiendo en muchas publicaciones católicas españolas, pero tiene especial relevancia en las páginas de uno de los mejores diarios de España, órgano oficioso del partido. Tal vez el año 1933, tras la formación del mismo, y en época previa a los comicios, este espíritu combativo está más presente que nunca, y se multiplican las ocasiones y lugares de su entrenamiento. Tras el triunfo electoral hay una cierta pausa, porque es la hora de la reflexión y

${ }^{59}$ La utopía anarquista bajo la Segunda República española..., p. 258. Muy importante, y ya clásica, a pesar de su unilateralismo, es la obra de MONTERO, J. R., La CEDA: El catolicismo social y político de la II República, 2 vol., Ediciones de la Revista del Trabajo, Madrid, 1977; para nuestro caso, especialmente las pp. 111-127 y 289-309. 
de la aplicación de los principios y lemas anteriores. Un cierto reposo tras las duras luchas del bienio.

En editoriales, artículos de colaboración, sueltos de todo tipo, manifiestos electorales, manifiestos de protesta, hojas y carteles de propaganda, especialmente en las semanas de pre-campaña y campaña electorales de finales de ese año, el socialismo aparece, sin muchas distinciones, como el enemigo más poderoso, por ser el más organizado. Como "el enemigo común”. Las declaraciones constantes en pro de la justicia social de periódicos y de políticos católicos palidecerán ante su constante oposición a cualquier tipo de socialización, en las Constituyentes; luego, contra la débil reforma agraria, y siempre contra los errores y los "delirios" socialistas.

Parte activa de la tipología general aplicable a los revolucionarios -seres inferiores, pasionales, orgullosos y envidiosos, carentes de valentía y honor-, los socialistas españoles, el partido socialista español, o el socialismo -como a veces se escribe, elevando el término a categoría permanente y universalaparecen una y otra vez como ineptos e incapaces para toda obra de gobierno; desmesurados en relación a cualquier capacidad administrativa a la hora de emprender reformas graves; limitados en horizontes espirituales; dotados de escaso bagaje ideológico; despreciadores de valores y virtudes individuales; violentos en cuanto encerrados en su lucha de clases; aborrecedores de jerarquías y riquezas; carentes de todo sentido nacional... En definitiva, los socialistas españoles no sirven para gobernar el país. Son una "secta" en el sentido más limitado y estrecho de la palabra. Todo su programa se reduce a destruir.

Este elemental acervo ideológico-político, asignado al enemigo congénito, está demasiado presente, muchas veces difuminado y difuso, en miles de páginas que he podido leer en toda clase de revistas eclesiásticas, populares o no, periódicos de provincias, sermonarios, libros y folletos de apologética, hojas volanderas, panfletos de propaganda... Y no es tampoco difícil encontrar, por ese tiempo, en los discursos de los oradores mitineros de la derecha católica expresiones ofensivas y groseras -de las que están llenas igualmente los diarios laicistas y, no digamos, la abundante literatura anticlerical y antieclesial, tan aburrida como demagógica-, contra los socialistas españoles: "pigmeos antiespañoles"; "reyezuelos", "dictadores", "abominables"...

Frente al marxismo y el republicanismo de izquierda los periódicos y líderes políticos católicos, un tanto fascinados al principio, como veremos, por los triunfos totalitarios en Italia y Alemania, ponderarán ciertos valores del régimen fascista aplicables al "Estado Nuevo", que comienzan a diseñar: el nacionalismo patriótico, su carácter antimarxista y antidemocrático, su capacidad organizadora, su exigencia de la disciplina, su ímpetu juvenil, el arte de su propaganda... Aunque sin querer copiar el modelo totalitario y pagano de los modelos estatistas alemán o italiano, defenderán el Estado autoritariocorporativo de base social, similar al "Estado Nuovo" portugués de Oliveira 
Salazar, opuesto al sistema liberal y a sus instituciones fundamentales, como los partidos políticos y el parlamento democrático ${ }^{60}$.

Pero no todos los enemigos venían de fuera. La división intergubernamental y no sólo intra-partidista -caso del PRRS- se hizo evidente en las elecciones del 2 de septiembre para el Tribunal de Garantías Constitucionales, compuesto por 25 miembros, 21 de ellos electivos, 15 de los cuales se elegían en una elección de segundo grado por los concejales de las Regiones. Los antigubernamentales, con 33.029 votos, obtuvieron 10 vocales: 4 radicales, 3 cedistas, 1 tradicionalista, 1 nacionalista vasco y el famoso contrabandista mallorquín, ex diputado liberal-albista a Cortes y magnate capitalista Juan March, encarcelado en Alcalá de Henares ${ }^{61}$. La mayoría gubernamental, dividida o mal unida, consiguió 17.869 votos, y 5 vocales, con buenos resultados sólo en Cataluña, Galicia, Extremadura, Asturias y Murcia, y un representante por cada partido: PSOE, ERC, PRSS, AR y PRG. El Gobierno, ya sin capacidad coordinadora, ni controló ni se cuidó siquiera de las elecciones.

El presidente del Consejo declaró el día 6 ante las Cortes que no se podía atribuir significado político a las elecciones llevadas a cabo en los municipios que llamó en una ocasión "burgos podridos" y en las celebradas para un tribunal que no era un órgano de gobierno. Reconoció, sin embargo, que era una "advertencia seria" y que, si los republicanos, divididos como estaban, rompían la "coalición electoral", base del propio Gobierno, los principios de su política se hundían. Ganó la votación de confianza en la Cámara, pero el presidente de la República, que iba más lejos, le retiró de hecho la suya y le obligó moralmente a dimitir ${ }^{62}$.

\footnotetext{
${ }^{60}$ La utopía anarquista..., pp. 266-273.

${ }^{61}$ En estas elecciones, el partido radical, el más votado de los partidos de la oposición, dejó libertad a cada región para que pactara "con los afines aquellas alianzas circunstanciales que se estimen convenientes". El Partido Republicano Radical (1908-1936)..., p. 375.

${ }^{62}$ También en sus apuntes de 1937 escribe Manuel Azaña: "Las discordias, la hostilidad entre republicanos y socialistas por esas provincias y esos pueblos dio su primer fruto político en la elección, a fines de agosto, de los vocales para el Tribunal de Garantías. Otros frutos peores había de dar. Los partidos de la coalición no supieron ni quisieron llegar a un acuerdo o una disciplina común para estas elecciones. En cada región electoral y dentro de cada región, en cada Ayuntamiento, el partido o la facción dominante hizo lo que le dio la gana. El Gobierno había acordado estar neutral en la elección, no darle carácter político, no prestarse a que fuera una votación de confianza en el Gobierno o de censura. Resultaron elegidos algunos republicanos y socialistas, pero los más eran de la derecha, incluso monárquicos y hombres de la Dictadura. (...). Los ánimos, ya encrespados, se enfurecieron. Vinieron los reproches, las imputaciones de falta de lealtad, etcétera. Los republicanos se quejaban de que sus candidatos habían sido atropellados por los socialistas; éstos de que los republicanos no habían votado con disciplina. Por primera vez el oleaje alcanzó al Ministerio. En el Consejo, Largo, recogiendo los agravios de los socialistas, me dijo solemnemente que la coalición electoral republicano-socialista estaba rota: "Entonces -repuse-
} 
Volvieron a pasar por el palacio republicano los representantes de los partidos políticos y todo el cortejo de notables que a don Niceto tanto le gustaba y le colmaba sus ilusiones de gobernante regio, culto y benéfico: Unamuno, Marañón, Sánchez Román o Álvarez (Melquíades). Alejandro Lerroux, el líder republicano radical, aconsejó al jefe del Estado la formación de un Gobierno exclusivamente republicano para la disolución de las Cortes, mientras los representantes de los partidos gubernamentales eran favorables, por entonces, a uno de concentración republicano-socialista. Don Niceto optó por la concentración republicana sin más, pero no por la disolución de la Cámara, que recelaba encomendar a un político entonces tan avinagrado como Lerroux.

Después de muchas idas y venidas, que dejaron de manifiesto las divisiones políticas y personales de los políticos republicanos, aun dentro de cada partido, el viejo zorro radical presentó, el día 12 de septiembre, un nuevo ministerio con 6 ministros radicales, 2 radical-socialistas, 1 de AR, 1 de ERC, 1 republicano gallego (PRG), 1 independiente, y 1 de la minúscula Izquierda Radical-Socialista, la primera escisión del PRRS. Ministerio que fue muy mal visto por los sectores izquierdistas y gubernamentales de los partidos republicanos $^{63}$. Por vez primera las juventudes socialistas y comunistas se manifestaron juntas en las calles de Madrid contra el nuevo Gobierno.

se habrá roto todo”. Obras Completas, IV ..., p. 645.- Marcelino Domingo nos da algunos detalles esenciales de esa doble decisión. Cuando el presidente del Consejo, en nombre del mismo, le pidió la confianza, tras recibir la de la Cámara, el presidente de la República les mostró el deseo, con sus circunloquios habituales, de que antes de hacer ningún cambio, se aprobaran las disposiciones sobre la sustitución de la enseñanza religiosa y la ley de arrendamientos rústicos, todavía en la comisión parlamentaria. Cuando Azaña insistió, don Niceto les preguntó a todos y a cada uno de los ministros: a) si creían que "el Gobierno y la mayoría estaban quebrantados"; b) si la permanencia del actual Gobierno posibilitaba o dificultaba "la constitución de la concentración republicana", y c) si el mismo Gobierno era "el más indicado para afrontar las elecciones municipales". Preguntas que traslucían la evidente intención del jefe del Estado. Los ministros le pidieron un día de reflexión. A la mañana siguiente, Azaña le presentó la dimisión, unánimemente acordada, y Alcalá Zamora, "después de un discurso emocionado, trascendente", se la aceptó. Era la hora de "un cambio profundo, abismal, en el destino de la República" escribe el siempre grandilocuente ministro radical-socialista. La experiencia del poder..., pp. 313-314.

${ }^{63}$ Según Vidarte, Lerroux ofreció carteras a Sánchez Román, Salvador de Madariaga, Ortega y Gasset, Marañón, e incluso a Francisco Franco, capitán general de Baleares. Todos habrían declinado la invitación. Las Cortes Constituyentes..., p. 628. Octavio Ruiz Manjón, en su libro, citado, sobre el partido radical añade, entre los invitados por don Alejandro a formar Gobierno, el nombre de Moles: Juan Moles, republicano histórico catalán, ex diputado y senador con la Solidaridad Catalana, gobernador civil de Barcelona (1932-1933) y alto comisario en Marruecos (1933), así como el del médico Pío Del Río Ortega, mientras omite el de Marañón. Afirma el autor que la oposición al nombramiento de tales personajes provino sobre todo de los propios militantes republicanos, opuestos, por un motivo o por otro, según cartas enviadas al "Jefe", a la formación de un gabinete de ilustres, ajenos a la política o ajenos al partido lerrouxista. El Partido Republicano Radical (1908-1936)..., p. 377. 
Con la sola ausencia de Cordero, se reunía la dirección socialista, el 11 de septiembre ${ }^{64}$, para formar criterio y dar al grupo parlamentario "la orientación precisa" con vistas al debate político en la Cámara. Algunos de los dirigentes socialistas, contrarios a la solución de la crisis, que ya conocen -Cabello, Carrillo, Fabra, Vidarte-, se muestran cautos antes de la declaración ministerial en las Cortes. Fernando de los Ríos, por ejemplo, es contrario a manifestar con antelación una conducta de franca oposición al Gobierno constituido, ya que "no hubo molestia para nadie en la tramitación y desarrollo de la crisis y que no se puede hacer declaración sin antes conocer las que pueda hacer al presentarse al Parlamento el nuevo Gobierno". Prieto, por el contrario, considera inevitable el tener que declarar la "hostilidad al gobierno Lerroux", pero estima que no es ahora el momento de hacerlo; que lo importante ahora es "hacer resaltar la conducta del partido y lo sacrificios realizados por el mismo a favor de la República, no teniendo respeto alguno al nombre de Lerroux, por estimar que su presencia en la Presidencia del Gobierno significa una provocación constante contra la obra revolucionaria realizada desde la implantación de la República hasta la fecha”.

Habla, como siempre, al final de la discusión, el presidente Largo, favorable a una declaración solemne de que, en virtud de la conducta seguida por los elementos republicanos al prestar su colaboración personal al gobierno de la República, "quedan rotos todos los compromisos contraídos entre los republicanos y nosotros en la gestación y desarrollo del movimiento revolucionario, y que por tanto cada Grupo político y cada Partido recobra plenamente su independencia para seguir el camino que estima pertinente la defensa de sus ideales". Este criterio es aceptado por toda la ejecutiva y se someterá a la deliberación del grupo parlamentario para que, si así lo estima, lo haga suyo y designe la persona que, en nombre del mismo, ha de defenderlo en el debate político.

En aquellas tensas circunstancias el nuevo Gobierno Lerroux era tan débil, que, tras la amenaza de la UGT de convocar una huelga ferroviaria que la impidiera, se vio obligado a prohibir la asamblea de la CEPA, convocada en Madrid para el 18 de septiembre. La nueva Confederación patronal agraria había reunido en anteriores convocatorias a miles de agricultores, que protestaban contra algunas leyes sociales, iniciativa del ministro Largo Caballero, o contra ciertas aplicaciones de las mismas. El comité organizador de la asamblea elevó su protesta en los tonos más contundentes e hizo referencia una vez más a "la ruinosa y nefasta actuación del marxismo", a la vez que publicó el proyecto de conclusiones que pensaba presentar a los representantes de los agricultores españoles. Ente ellas estaban: la derogación de la ley de términos municipales, la libertad de empleo de maquinaria agrícola, la fijación de salario mínimo y jornales máximos antes de empezar el año agrícola, la revisión

${ }^{64}$ AH 20-2, p. 81. 
urgente de la legislación social, la presidencia de los jurados mixtos por magistrados asesorados por técnicos... Con esa ocasión se creó también, como lo habían hecho poco antes otras organizaciones patronales, un "comité de enlace de entidades agropecuarias", que se encargó de exponer la penosa situación de las mismas al presidente del Gobierno, a los ministros de Agricultura y de Trabajo y a todo el país ${ }^{65}$.

Los días 23-25 de septiembre, en el III Congreso extraordinario del PRRS se consumó la prevista, anunciada, deseada o temida, división en dos del partido, al que muchos denominaban "de los jabalíes" y el mismo Albornoz, uno de sus fundadores, llamó "una olla de grillos". Se quedó con la sigla la fracción más antigubernamental, encabezada por el veterinario leonés, y diputado por León, Félix Gordón Ordás - llamado irónicamente por algunos "el Marañón de los veterinarios"-, a quien siguieron 14 parlamentarios. La pilotada por el ex ministro de Instrucción Pública y Agricultura, cercano a los socialistas, Marcelino Domingo, consiguió la adhesión de 26 diputados a Cortes y se denominó desde entonces PRRSI (independiente). Otros 12 parlamentarios quedaron en tierra de nadie ${ }^{66}$. También el pequeño partido federal se había fragmentado, una vez más, en dos grupos irreconciliables.

\section{EL COMITÉ NACIONAL DEL PSOE (18 Y 19 DE SEPTIEMBRE)}

Los días 18 y 19 de septiembre se reunió el comité nacional del partido socialista, presidido por Francisco Largo Caballero, con asistencia de todos los miembros de la comisión ejecutiva y de los quince representantes regionales (un suplente, en el caso de Castilla la Vieja), además de José Castro, todavía presidente nacional de las Juventudes Socialistas ${ }^{67}$.

Con antelación habían recibido todos sus componentes la Memoria sobre la gestión de la Comisión Ejecutiva del Partido Socialista desde el último Congreso hasta la fecha ${ }^{68}$. En ella se informaba brevemente sobre el ingreso de agrupaciones socialistas en el partido desde el mes de octubre de 1932; los resultados de las elecciones para el comité nacional; la reorganización de la secretaría; la gráfica socialista; el órgano oficial El Socialista; las relaciones con la Internacional Socialista y con los partidos de la misma; las elecciones

${ }^{65}$ La patronal ante la II República..., pp. 158-159. El vicepresidente del comité de enlace, Adolfo Rodríguez Jurado, y el secretario del mismo, José María Hueso Ballester, fueron candidatos en la listas del Frente Antimarxista por Madrid-capital y por Madridprovincia, respectivamente en las elecciones legislativas de noviembre y diciembre.

${ }^{66}$ Marcelino Domingo, que dedica no pocas páginas de su libro a vapulear a sus teóricos congéneres políticos, atribuye la pertinaz indisciplina y rebeldía de los disidentes a que, al fin y a la postre, "eran de derechas. Después se ha visto claro que era así". La experiencia del poder..., p. 307.

${ }^{67}$ Acta de la reunión celebrada por el Comité Nacional del Partido Socialista el día 18 de septiembre de 1933, AH 20-4, pp. 66-88.

${ }^{68}$ AH 19-18, pp. 1-12. 
parciales municipales y al Parlamento de Cataluña; las relaciones con las federaciones; los grupos socialistas en el extranjero; las delegaciones y conflictos entre organizaciones; los congresos de las federaciones; la ley de incompatibilidades; la propaganda; la tesorería... Se transcribían los breves informes enviados por quince provincias sobre las elecciones municipales de abril. Las agrupaciones socialistas en el segundo semestre de 1932 eran 1337, y en el primer semestre de 1933, 1386.Los afiliados a las mismas eran en el mismo período de 1932, 73857, más 954 afiliados directos, mientras que en 1933 llegaban a 81777, más 754 directos.

De todos estos asuntos trataron extensamente los miembros del comité nacional durante toda la mañana del día 18 y buena parte de la tarde. Sobre el frente único, aprobaron sin discusión el apartado de la Memoria: "Algunas organizaciones han consultado a la Ejecutiva si debían aceptar el ofrecimiento de algunas entidades comunistas para constituir el frente único, significándose a todas que la Ejecutiva no había adoptado acuerdo alguno sobre este particular" ${ }^{\prime \prime}$. Igualmente aprobaron la opinión de la comisión ejecutiva de que los diputados a quienes afectara la reciente ley de incompatibilidades debían optar siempre por los cargos de elección popular.

Entra luego el presidente a tratar de la situación política, comenzando de la última crisis, que quedó planteada por el deseo del presidente de la República "de formar un Gobierno de concentración republicana, sin que esto sirviera de ofensa para los socialistas". Y aquí menciona Caballero su propuesta fundamental que ya conocemos. "Decíamos, además -añade-, que para lo sucesivo nuestra posición sería ni de benevolencia ni de hostilidad, sino de oposición socialista, procediendo dentro del Parlamento con arreglo a nuestros principios". La proposición fue llevada al grupo parlamentario, "que la aprobó por unanimidad”. También el comité nacional aprueba unánimemente mantener la misma resolución.

Tras una crítica puntual de un delegado al diario El Socialista, por una supuesta deficiencia en la publicación de noticias sobre la organización socialista en Sevilla, a la que responde el director del diario, Julián Zugazagoitia, venido expresamente para la ocasión, el presidente Largo, a petición de Cabello, manifiesta que la ejecutiva "está muy satisfecha de las marcha del periódico, en su aspecto de redacción y presentación. Es aprobado".

En relación a las elecciones municipales, previstas en principio para fechas próximas, el comité nacional, tras escuchar al presidente sobre la comi-

${ }^{69}$ Por ejemplo, en la sesión de la CE, del 29 de marzo de 1933, se da cuenta de que la agrupación socialista de Almería ha recibido una comunicación de los comunistas de aquella población invitándoles a formar un "frente único" "contra el peligro que supone la intromisión del fascio en España", y dicha agrupación pide normas concretas para proceder a formar ese frente único. Se acuerda contestarle que "no procede la formación de tal bloque, por ser el Partido Socialista a quien compete dictar normas de carácter general para oponerse a toda acción represiva de los enemigos de la República”, AH 20-2, p. 47. 
sión electoral conjunta, ya constituida, entre el partido y el sindicato socialista, acordó por unanimidad mantener el criterio de la CE de que no pudieran aliarse las agrupaciones o federaciones "con ningún otro organismo que la Unión General de Trabajadores, sin consultar con la Ejecutiva del Partido, tanto para las elecciones municipales como generales". Acuerdo que será aducido en numerosas ocasiones, como veremos más tarde, ante las frecuentes consultas tras la convocatoria de las elecciones legislativas de noviembre. En cuanto a la propaganda política, se conviene en que los propagandistas del partido no podrán intervenir en actos políticos o sindicales que no estén organizados por entidades del PSOE, de las JJSS o de la UGT. "Será preciso en cada caso la autorización de la Comisión Ejecutiva para celebrar actos de conjunción o de "frente único", con elementos no pertenecientes al Partido".

Pero la parte más enjundiosa del comité estaba reservada para la mañana y la tarde del día 1970: "Actitud a seguir del Partido Socialista ante el momento político". Largo Caballero, actuando siempre como presidente, introduce sibilinamente el tema, al manifestar que conviene "conocer el espíritu de la clase trabajadora de provincias", puesto que "se están recibiendo telegramas que el que (sic) más suavemente aconseja, dice que nos apoderemos del Poder".

Los delegados regionales dieron cuenta del estado de cosas de su partido y de otras fuerzas regionales en cada una de las regiones españolas. Según el delegado extremeño, Antonio Canales, la situación de Extremadura era "trágica" por la pobreza general y la crisis de trabajo, y él se manifestaba partidario de "no tener tolerancia con los gobernantes actuales, yendo al asalto del Poder por los medios que sean". Algo parecido sobre la situación en su tierra contaban los delegados de la Andalucía oriental y occidental, Francisco Azorín y Adolfo Moreno, respectivamente. Aunque varios distinguían entre unos republicanos y otros, todos se sentían aliviados por haber dejado el Gobierno de la República y todos eran opuestos al de Lerroux.

Oídos los informes de sus compañeros, Moreno proponía, además de ratificar el acuerdo de la comisión ejecutiva y apoyar "una ruda y completa oposición al Gobierno actual", que en caso de un próximo decreto de disolución de las Cortes "se vaya decididamente a apoderarse del Poder, otorgándole a la Ejecutiva a este efecto un amplio voto de confianza para que ella adopte los acuerdos y medidas conducentes a tal finalidad". Una propuesta pareja era la del delegado de Castilla la Nueva, Rafael Henche, concejal de Madrid. El mismísimo Caballero interviene entonces para calmar un poco los ánimos. No cree, tampoco él, "en la posibilidad de la conquista del Poder por la violencia, pues no basta decirlo en proposiciones", y hay que examinar si se está en condiciones de hacerlo. Ve, eso sí, mucho descontento, una gran irritación,

${ }^{70}$ Acta de la reunión celebrada por el Comité Nacional del Partido Socialista el día 19 de septiembre de 1933, AH 20-4, pp. 89-97. 
porque "ha matado muchas esperanzas la República" y se desea por todas partes que "el Partido Socialista proceda como tal". Le parece más conveniente una resolución para protestar porque el Gobierno no haya ido al Parlamento, como era su obligación, y por "el intento de anular la legislación social". Propone seguidamente una ponencia de tres compañeros, y se nombra al mismo Largo Caballero, a Prieto y al delegado de Levante, Manuel Molina Conejero, que en su informe ha insistido en lo que acaba de ponderar el presidente.

Habla luego Fernando de los Ríos, que recalca igualmente el peligro que corre la legislación social, mientras le parece "expuesto y ridículo" que se plantee la toma del poder. Asimismo Prieto, que no se considera el mejor intérprete de todo lo dicho en el comité y por eso duda de que sea un buen ponente, descarta "todas las indicaciones a un Poder inmediato" y rechaza rotundamente que estén en condiciones de conseguirlo. Teme que con el Gobierno de Lerroux las derechas se adueñen de las organizaciones socialistas y sostiene la alianza con los republicanos de izquierda, para no quedar "en un completo aislamiento parlamentario". A este último punto le replica Caballero que se pueden hacer alianzas en cada provincia.

A las seis menos cuarto de la tarde del día 19 se reanudó la sesión. Y el compañero Indalecio leyó el dictamen redactado por él mismo y compuesto por los tres miembros elegidos de la ponencia. Tras recoger en una larga introducción los argumentos expresados por los delegados regionales, llega a los cinco puntos, que, coincidentes con la línea de conducta que se trazó el grupo parlamentario al aceptar la propuesta de la comisión legislativa, se convierten en resolución del comité nacional:

" 1 ․ Su absoluta disconformidad con el cambio político que entraña la solución de la última crisis ministerial, solución francamente enderezada hacia un retroceso en la marcha política y social de la Republica.

$2^{\circ}$. Su protesta enérgica por no haberse apresurado el Gobierno a convalidar ante las Cortes los poderes que le han sido otorgados por el presidente de la República, ya que la plenitud de autoridad no puede tener por base la confianza presidencial cuando ésta no aparece unida a la del Parlamento, igualmente indispensable y de rango no inferior. Sólo a un Gobierno que hubiese demostrado la existencia de la confianza parlamentaria le sería lícito demorar las sesiones hasta la fecha infranqueable señalada por la Constitución; mas cuando no se ha obtenido esa prueba, la clausura parlamentaria significa burla y menosprecio por los principios constitucionales.

$3^{\circ}$. Su firme resolución de sumar el esfuerzo del Partido al de la Unión General de Trabajadores para defender sin desmayo el cumplimiento de la legislación social, estando dispuesto, por otra parte, a realizar todo género de sacrificios a fin de impedir el menor retroceso en las conquistas alcanzadas. El Comité Nacional declara que la legislación social de la República, lejos de rebasar los límites establecidos en el solemne pacto revolucionario de 1930, no ha llegado siquiera a ellos. 
$4^{\circ}$. Su decidido propósito de estimular a las Federaciones, Agrupaciones y afiliados para que se entreguen con ardor entusiasta a la propaganda intensa, política y sindical, debiendo encauzar esa propaganda hacia el robustecimiento de las organizaciones del Partido y de la Unión General de Trabajadores, como instrumentos esenciales de la lucha política y sindical.

$5^{\circ}$. Su fe inquebrantable en los altos destinos del Partido socialista que, siendo el más fuerte pilar de la democracia española, habrá de ser en un mañana próximo la base inconmovible de un régimen de justicia".

No gustó a todos este último párrafo. El mismo Vidarte pidió que se hiciera constar "que se debe ir a la conquista del Poder". Y se enzarzó en un vivo diálogo con Prieto sobre la democracia, que no negaba, pero que tampoco era la burguesa; ni combatía la República, como su colega bilbaíno le reprochaba, sino que constataba "una gran desilusión en los pueblos por el régimen actual".

En este momento entró Largo en la disputa. Es todo un guión de lo que viene sosteniendo hace tiempo y va a sostener sobre todo en la próxima campaña electoral: "Yo he querido interpretar, no sé si me habré equivocado, que los compañeros no es que renieguen de la República, pues el Partido socialista está dispuesto a sostenerla, ahora que el Partido socialista no renuncia a su postulado. Creo que debemos vivir en la realidad y la palabra "democracia" está para la clase trabajadora un poco en desuso por haber estado rodando en todo el historial político de España. Repito que esto no es ir contra la República. Lo que sí decimos, cumpliendo con ello deberes elementales, es que a la República hay necesidad de darle un contenido social a tono con las necesidades del momento presente. Precisa dar una mayor envergadura social, sin la cual nada se podrá resolver".

Los compañeros disidentes redactaron un nuevo punto quinto, que quedó así: "Su fe inquebrantable en los altos fines del Partido socialista; su resuelta decisión de defender la República contra toda agresión reaccionaria y su convicción de la necesidad de conquistar el Poder político como medio indispensable para implantar el socialismo".

Prieto está de nuevo en contra de lo que él llama "el deseo de adueñarnos del Poder político", pero, puesta a votación el nuevo párrafo, queda aprobado por 14 votos a favor y 3 en contra; uno de ellos el de "don Inda", que pidió constase su voto en contra. Eran las ocho y media de la noche. 